Claremont Colleges

Scholarship@ Claremont

CGU Theses \& Dissertations

CGU Student Scholarship

2014

\title{
Maintaining Religious Identity in the Wake of Interfaith Dialogue
}

Teresa A. Crist

Claremont Graduate University

\section{Recommended Citation}

Crist, Teresa A.. (2014). Maintaining Religious Identity in the Wake of Interfaith Dialogue. CGU Theses \& Dissertations, 90. http://scholarship.claremont.edu/cgu_etd/90. doi: 10.5642/cguetd/90

This Open Access Master's Thesis is brought to you for free and open access by the CGU Student Scholarship at Scholarship @ Claremont. It has been accepted for inclusion in CGU Theses \& Dissertations by an authorized administrator of Scholarship @ Claremont. For more information, please contact scholarship@cuc.claremont.edu. 
Maintaining Religious Identity in the Wake of Interfaith Dialogue

By

Teresa A. Crist

Claremont Graduate University

2014

(C) Copyright Teresa A. Crist, 2014

All Rights Reserved 


\title{
APPROVAL OF THE REVIEW COMMITTEE
}

This thesis has been duly read, reviewed, and critiqued by the Committee listed below, which hereby approves the manuscript of Teresa A. Crist as fulfilling the scope and quality requirements for meriting the degree of Master of Arts in Religion.

\author{
Patrick Q. Mason, Chair \\ Claremont Graduate University \\ Chair of the Department of Religion \\ Howard W. Hunter Chair of Mormon Studies
}

Maritza Salazar

Claremont Graduate University

Assistant Professor of Organizational Behavior 


\section{Introduction}

One of the most salient questions of our time is: how can we all get along? Although the world is getting smaller with technological advances and greater interconnectivity, the goal of world peace sometimes seems farther away than ever. We are frequently confronted with difference, and how we respond to that difference determines our relationships and development as a global society.

The confrontation with difference is an especially large challenge when it comes to religion and religious beliefs. Because religion is integral to so many, it becomes a sticking point in negotiations, conversations, and policy development. Even for those without particularly strong religious convictions, religion must be considered in their interactions with those who do. It is precisely that interaction that I seek to further understand. Engaging in dialogue with those of different faiths or value systems brings to the surface myriad difficulties, chief among which is the challenge of simply coming together to begin the conversation. The most appealing approach to that challenge is often to find some sort of common ground on which everyone can agree, a foundation upon which relationships can be built. That common ground, however, can be just as harmful to the end-goal of dialogue as not having dialogue in the first place. Common ground approaches focus on similarities, ignoring or discounting the differences which both make us who we are and make conversations difficult to have. In ignoring differences, participants are forced to relegate salient aspects of their beliefs to a private (unseen) arena, where they may wither away, dulled from disuse, eventually no longer relevant as an identifier. The foremost question I seek to answer, then, is the following: How can religious identity be maintained in light of such approaches to dialogue? 
The short answer is that it can't. A different approach to interfaith dialogue is needed in order to both allow and affirm the differences that are the reasons for which we need to have conversation in the first place. One such model that does this is the acceptance model, which is represented by the works of S. Mark Heim in his book Salvations. In this model, religious differences are acknowledged and affirmed in the course of interfaith interaction, refusing to presume superiority or singular access to the divine by any one group. Rather than assuming that religions are mere interpretations of something that is beyond any one person's or group's grasp, religions all seek different ultimate ends. Under such a conceptualization, interfaith dialogue can be conducted without leaving differences at the door. Instead, differences can be engaged, even to the point of conflict and argument, which are inevitable results of such dialogue. Differences don't have to be reconciled, and are in fact unlikely to be so when maintaining religious identity. The acceptance model is extremely challenging to actualize. It may be satisfying to have a theoretical discussion enjoining the acceptance of irreconcilable differences, but actually hosting such an activity on the ground level in any kind of organization is rife with impediments. It is with this in mind that I seek to explore the interfaith organizations that are making the attempts. By observing their structure and methods and the nature of the interaction they support, we can determine which groups, if any, are truly interfaith according to the acceptance model and which are successful in the dialogue they encourage. The success of any one group is a positive step toward bringing people together in relationship while making room for their religious identities. 


\section{Chapter Layout}

This thesis is organized into three chapters, each of which addresses distinct, but ultimately related issues. The first chapter introduces the concept of identity from a social science perspective, working toward a definition of identity that is most applicable to the multivariate and complex situation which has arisen in light of a globalizing world. This is followed by a more particular exploration of religious identity as distinct from but imperative to identity writ large. Once the salience of religious identity has been elaborated, I turn to a discussion of the problems that arise when identity is threatened, and what it is which issues those threats.

With a firmer understanding of identity, I move to the second chapter, wherein I discuss first the larger context of pluralism in which identity maintenance must occur. The careful consideration of different conceptions of pluralism leads directly into the discussion of two representative models for interacting and coexisting within such conceptions. A focused study and critique of the two models yields a preference for one model to another, rooted in its ability to better preserve and affirm religious identity, even within the diverse context of the world.

The third chapter is devoted to the appraisal of several organizations claiming to be interfaith-oriented. By assessing their own purported principles and intents, I judge whether they are truly interfaith, according the models and definitions elucidated in the two previous chapters. The successes and failures of the various groups mentioned contribute to the question of whether it is possible to carry out the difficult task of maintaining religious identity in a pluralistic world.

\section{Method}


To study identity, I explored the social psychological perspective, surveying research and case studies rooted in social identity theory. I chose such an approach (as opposed to one based in a philosophy or theory) because it allowed me to better understand empirical and experiential conceptions of identity. What happens on the ground level rather than on the theoretical plane is far more applicable to the issue of interfaith dialogue.

Philosophical and theoretical approaches were much more appropriate for the second chapter, where the different models themselves were under examination. In order to determine whether actualized interfaith groups were able to successfully implement idealized conceptions of interaction and identity maintenance, contemplating the latter was absolutely necessary.

In the third chapter, where I examine the efficacy of certain interfaith groups, I chose to engage with the information they presented to the world at large through literature publications, social media, and public statements. Assuming that a web master or PR representative of any one group screens the information disseminated to the masses, I studied the image that each group wished the world to see. Some groups explicitly listed the principles by which they operated while others, because of their size or structural organization, operate under implicitly expressed values. I also observed events and meetings of the groups, asking questions of the people available to confirm or contradict the principles that were publically advocated. 


\section{Chapter 1:}

An Exploration of Religious Identity: Importance and Influence

\section{What is Identity?}

The question of identity, of what it is that makes a person who they are, is a complicated one. Given that all the facets that make up the conceptual prism of identity - culture, genetics, personality, values, ethics, etc. - have spawned their own fields of study, it is hardly surprising that developing a comprehensive definition of identity has remained elusive. It is perhaps the case that the focus of different fields on individual aspects of identity has been problematic, leading to the practice of understanding identity only through one specific lens at a time. This problem can be negated - or at least reduced - by the careful consideration that one actually needs multiple lenses to see the broader picture and understand the composite nature of a person's identity. Such a view allows for the observation and study of singular aspects within identity without deleterious effects to the whole.

One way of looking at the composite picture of identity is through the study of culture. Just as prone to a multiplicity of definitions as identity itself, culture contains within it practices, rituals, beliefs, and other intangible identifiers. Culture as a defined term is often attributed to Edward Burnett Tylor, who stressed the importance of culture as acquired identifiers, learned knowledge, habits, art, morals, and customs, that set one distinct group apart from another. ${ }^{1}$ Later, in developing the now well-known concept of cultural dimensions, Geert Hofstede compared culture to "software of the mind," or "mental programming," which consists of patterns of thinking, feeling, and acting established early in life. ${ }^{2}$ This focus on the social and

\footnotetext{
${ }^{1}$ Edward B. Tylor, Primitive Culture: Researches into the development of mythology, philosophy, religion, language, art, and custom, Sixth Edition, (London: Murray, 1920), 1-26.

${ }^{2}$ Geert Hofstede, Cultures and Organizations: Software of the Mind: Intercultural Cooperation and its importance for survival, $3^{\text {rd }}$ ed. (New York: McGraw Hill 2010), 4-5.
} 
socialized constructs of culture is indeed relevant, but still narrow. Culture includes even more than this, in the form of inherited traits and personality. Some (including Hofstede) might argue that there is a very distinct difference between personality and culture ${ }^{3}$, but the line is in fact much ambiguous than they would purport, and it is that ambiguity which allows culture to blur into overall identity. Cultural identity (the determination of who one is based on those aspects of which culture consists) actually encapsulates all categories of general identity, as the concept of culture itself incorporates many different inherited traits, personality traits, and practices. A person's cultural identity is composed not just of values, norms, and beliefs, but also of affiliations and contextual cues that determine and augment a person's behavior and interactions.

Even cultural identity as a larger encapsulating term is presented with a greater challenge to serve as an umbrella term as increased globalization, residential mobility, and pluralism have diversified identity approaches to favor a postmodern consideration of context. Cultural identity is thus contingent on the understanding of reality as constructed and the inherent instability of that reality, leading to a multiple, if not fractured, vision of the self. Everyone has multiple identifiers, each one of greater or less significance in any given context. ${ }^{4}$ Much work has come of limited concepts like frame switching, elucidated by Hong, Morris, Chiu, \& Benet-Martinez, 2000, wherein an "individual shifts between interpretive frames rooted in different cultures in response to cues in the social environment. ${ }^{5}$ Hong et al. developed a study in which they primed bicultural individuals with symbols to encourage behavior within one of two internalized cultures. The idea was that frame-switching would occur based on the priming because the two

\footnotetext{
${ }^{3}$ Ibid., 7.

${ }^{4}$ See, for example, Selcuk R. Sirin and Michelle Fine, Muslim American Youth: Understanding Hyphenated Identities through Multiple Methods (New York: New York University Press, 2008). This excellent study addresses the "hyphenated selves" of Muslim Americans, referring to their "many identities, including their standings as Muslims and Americans, that are at once joined and separated by history, politics, geography, biography, longings, and losses," (3).

${ }^{5}$ Ying-yi Hong, et al. "Multicultural Minds: A Dynamic Constructivist Approach to Culture and Cognition” in American Psychologist, Vol. 55, No. 7, 2000. 709-720, emphasis mine.
} 
internalized cultures did not blend at all (Hong et al., 710). Naturally, an interpretive frame will vary when the context does, but that does not mean that one must look through only a single frame at any one given moment. The flaw in frame-switching thus lies in its absolutism. The presumption that one can only alternate among internalized frames rather than looking through myriad lenses ${ }^{6}$ to understand the world is too narrow an approach for understanding a more expansive concept of identity. A far less narrow conceptualization of identity can be found in the social identity complexity theory, wherein multiple frames can be held in place at once, leading to a more complex, multivariate identity rather than one limited by a dominating frame at any one given moment. ${ }^{7}$ Such a conceptualization is far more apposite, especially given the growing interconnectivity of peoples among the world

This increased interdependence of peoples among the world is manifest concretely in the process of globalization, defined by David Held, Anthony McGrew, David Goldblatt, and Jonathan Perraton’s seminal work on that topic: Global Transformations: Politics, Economics and Culture. Though the work is slightly dated, the authors' definitions and descriptions of the construct of globalization remain valid. They define globalization as the following: "a process (or set of processes) which embodies a transformation in the spatial organization of social relations and transactions $[\ldots]$ generating transcontinental or interregional flows and networks of activity, interaction, and the exercise of power." ${ }^{8}$ In the definition, "flows" refers to the dissemination of "artefacts, people, symbols, tokens, and information across space and time.”" Globalization is a very real process, measurable by such sociological and ethnographic data of

\footnotetext{
${ }^{6}$ As, for example, in Hong et al., 2000 and Saba Ozyurt, "Negotiating Multiple Identities, Constructing WesternMuslim Selves in the Netherlands and the United States," in Political Psychology 34 (2013).

${ }^{7}$ Marilynn B. Brewer and Kathleen P. Pierce, "Social Identity Complexity and Outgroup Tolerance.” Personality and Social Psychology Bulletin 31 (2005).

${ }^{8}$ David Held \& Anthony McGrew, David Goldbatt \& Jonathan Perraton, Global Transformations: Politics, Economics and Culture, (Stanford: Stanford University Press, 1999), 16.

${ }^{9}$ Ibid.
} 
population, industry, and economic statistics. Though there are many different opinions of what such changes and developments brought on by this process will actually bring in the future, there is no question that the world is not stable, and it is getting smaller every day. Such a discussion of globalization as a very real process in the world today is extremely relevant to any discussion of identity. Globalization increases the need for multiplicity of views in order to relate more fully both to the other people with whom one more frequently comes into contact and to understand the increased variation such contact causes within a single person. The exposure to and transfer of culture (in the form of ideas, information, tradition, products, and systems of thought) bears directly on identity.

Because of this increased variation of and within identity, a more useful and representative way of understanding its multiplicity is through a cultural mosaic, a concept elucidated by Georgia T. Chao and Henry Moon. A cultural mosaic is a "metaphoric conceptualization of multiple indicators of cultures used to describe an individual." ${ }^{10}$ These multiple indicators are different aspects of salient identity which, when observed as a whole, make up an individual's comprehensive cultural identity. Thus, all identities one might use in a self-concept are accounted for at all times, marking cultural identity as equivalent to overall identity. The different tiles within the mosaic can be divided into associative, demographic, and geographic categories. Associative tiles represent all the groups with whom an individual chooses to identify. Demographic tiles represent aspects of an individual that are generally physical or inherited, such as age, gender, race, and ethnicity. Geographic tiles represent those aspects of identity that are based on the physical aspects of a region, such as urban-rural, climate,

\footnotetext{
${ }^{10}$ Georgia Chao and Henry Moon, "The Cultural Mosaic: A Metatheory for Understanding the Complexity of Culture” in Journal of Applied Psychology, 90 (2005), 1128.
} 
or coastal-inland. ${ }^{11}$ One of the benefits of the cultural mosaic definition is that identity is constituted by the entire mosaic and not just one tile, a conceptualization which negates the difficulties encountered with the narrow views espoused in identity concepts like frameswitching. With the exposure to new knowledge, ideas, and other cultural aspects, new tiles are inevitably added to the mosaic. This in turn has an effect on overall identity - it might be homogenized to dominant ideals, Westernized or Americanized as many fear, leaving local cultural identities behind. ${ }^{12}$ The migration of culture and ideas might also lead to the development of an entirely new global identity, supra-related to local identities by being transnational or transregional, beyond or outside of previously constructed boundaries.

Context will inevitably play a large part in determining which indicator (tile) of one’s identity is most salient at any given moment. For example, a mother might be less inclined to think of herself as such when her children aren't around, and religion might be more salient when other identification markers such as nationality are either not visible or undervalued in a new dominant culture. Kay Deaux in "Reconstructing Social Identity” (1993) approaches the structure of identity hierarchically: sets of identities are related to categories of features or attributes. Particular positions may have important affective and behavioral correlates. ${ }^{13}$ Deaux described a study of women with lupus as exemplifying this: Patients for whom the identity of “me before lupus” was dominant showed significantly higher levels of depression than those for whom “me before lupus” was not prioritized. Thus, the importance or position given to any one aspect of identity can determine behavioral outcomes. ${ }^{14}$ In the case of a cultural identity,

\footnotetext{
${ }^{11}$ Chao and Moon, 1129-1131.

${ }^{12}$ Held, Global Transformations, 327. The authors talk here about hyperglobalizers, those who "predict the homogenization of the world under the auspices of American popular culture or Western consumerism in general." The hyperglobalizers tend to view globalization as determinedly denationalizing the world into a single global market, (3).

${ }^{13}$ Kay Deaux, “Reconstructing Social Identity,” Personality and Social Psychology Bulletin 19 (1993), 6.

${ }^{14}$ Ibid., 6-8.
} 
understood in the mosaic terminology, we would expect to see this phenomenon manifested in such behavioral patterns as cross-group interaction and acculturation. Identity constructed on the basis of multiplicity and complexity is far more open to the possibility that one aspect over another may be more salient and determinate of behavior.

\section{What is Religious Identity?}

From a generalized conception of identity premised on culture and the multivalent factors of which it is composed, I now turn to one specific aspect of identity, that of religion. A person's beliefs (whether they are religious or philosophical in their roots) bear heavily on the outward expression of her existence; indeed, a person's religion, ${ }^{15}$ informs and emphasizes his values, norms, beliefs, and practices, which make up the hallmarks of defined and conceptualized culture. $^{16}$

Religion, although it can be isolated for study, affects identity in all its manifestations. Though one might say this about any one tile of a person's identity mosaic, religion seems to be even more apposite to discussions of effects on identity because it does resonate with so many different aspects. Studying a geographic tile - a person’s origins in a desert climate and inclination to look at the world with a constant concern for the provision of water, for example has a much more limited effect radius on your overall identity. Religion, on the other hand, is often explicitly a world-view, not a lens, but the lens through which one understands the entirety

\footnotetext{
${ }^{15}$ I must insert here a note on the difficulty of defining religion in general before beginning to apply such a definition to the scope of identity. I would like to use something looser, a family resemblances approach to understanding religion, since I include as relevant to identity belief systems which are traditionally understood via transcendence characteristics as well as more philosophical systems. Thus secular humanists and atheists have a place in the discussion, for their beliefs influence their actions and identity just as much as one who participates in Christianity or Buddhism.

${ }^{16}$ Shweder, 1990, Kashima \& Gelfand, 2011, Berry, 2000
} 
of one's existence. The world-view constructed by religion is one of eternal relevance, so that in accepting it or being influenced by it, one uses it to measure their entire life. In an article discussing religious identity from a social identity perspective, Renate Ysseldk, Kimberly Matheson, and Hymie Anieman explain: "Religion differs substantially from these [other] constructs [gender identity, political identity] in that it may also invoke epistemological beliefs regarding what can (or cannot) be known as well as ontological beliefs regarding what can (or cannot) exist...”17 Religion can and does claim itself as relevant even beyond a single individual, which makes it all the more compelling. The fact that one is either born into a religion and steeped in it from infancy or chooses a religion after a careful thought and learning process points to its inseparability from a person’s very being. Religion, while obviously not the only identifier within one's mosaic, remains especially important in the construction of identity, not only of the self, but of how that self relates to the world at large, by transcending it through ideological, social, and spiritual contexts.”18 Such an important part of identity cannot be overlooked or underestimated.

Within the cultural mosaic, the religion or religious affiliation tile is perhaps most commonly described as an associative tile, but depending on its strength, it is also demographic, an indicator of identity that is a characteristic inherited or totally integral to and inseparable from a person's self-identification. An initial religious affiliation after conversion might only be associative, but once religion is a strong enough self-identifier, it ought to be given more consideration. Religion has a great effect on identity formation, not only as a category of definition, but in maintaining that category. Such an identity, one in which in-group members

\footnotetext{
${ }^{17}$ Renate Ysseldyk, Kimberly Matheson, and Hymie Anisman, "Religiosity as Identity: Toward and Understanding of Religion from a Social Identity Perspective.” Personality and Social Psychology Review Vol 14 (2010): 61.

${ }^{18}$ Pamela Ebstyne King, "Religion and Identity: The Role of Ideological, Social, and Spiritual Contexts," Applied Developmental Science, Vol. 7, No. 3 (2003): 197.
} 
hold strong convictions, "will likely bring about benefits to personal well-being, equaling or exceeding those associated with other group memberships." ${ }^{19}$ Religion, then, is as strong a predictor of behavior or world-view as the values tied to "general treatments of culture," which are usually demographic tiles within the cultural mosaic and often given more weight in the consideration of the expression of cultural identity. ${ }^{20}$

To ignore or marginalize religion in the unpacking of cultural definitions is to neglect something essential in our understanding of the phenomenon of cultural identity as a whole. In fact, for many people religious identity can be equated with identity writ large, as religion is actualized in all aspects of life. For a person of strong conviction, there is no part of one's existence that remains untouched by religion or a belief system, as it is both the lens through which one views the world, but also the guidelines and directive through which one interacts with it. Even for those who claim religion as a less pervasive force in their lives, it is often still relevant eschatologically and ontologically. One may be a “Christmas and Easter Christian”21, but they are still Christian, and do mind the bare minimum when it comes to religiously established guidelines. Their eternal identity remains relevant, or else they wouldn’t even maintain the minimum requirements for belonging.

Earlier I mentioned the homogenization thesis and emerging global identities which usurp local cultural identities. The idea of an overarching identity developing due to the decrease in national or ethnic boundaries is not a new one. Those studying the acculturation process have been observing the effects migration and cultural exposure have on a person's cultural identity, even to the point of developing a rubric of four strategies (Berry, 2000). These

\footnotetext{
${ }^{19}$ Ysseldyk et al, “Religiosity as Identity,” 62.

${ }^{20}$ Chao and Moon, 1130.

${ }^{21} \mathrm{~A}$ Christmas and Easter Christian is one who, rather like a lapsed Catholic, only attends church - or possibly even considers his religion - on the highest holidays of the liturgical year.
} 
include assimilation (the abandonment of one's original culture in favor of the dominant culture), integration (the identification with both the dominant culture as well as the original culture), separation (the rejection of the dominant culture in favor of retention of the original culture), and marginalization (the rejection of both the dominant culture and the original culture). One can see fairly quickly that encounters with new and varied cultures bear quite strongly on identity. The most positive form of acculturation for the purposes of a feasible mosaic identity is that of integration, because both new and old cultures remain relevant. Assimilation, separation, and marginalization are negative strategies, requiring the loss of at least one tile in the mosaic, leading to a reduction of identity, though the former two also involve the maintenance of at least one aspect of identity.

Interestingly Jonas R. Kunst \& David L. Sam, in their 2013 article "Expanding the Margins of Identity: A Critique of Marginalization in a Globalized World,” posited that marginalization is not such a negative form of acculturation as might be assumed at the outset. Rather than being a loss of identity overall, their research suggests that marginalization "may in fact not involve an empty or confused cultural self-concept, but simply a self-concept that transcends the ethno-national paradigm by, for instance taking the form of identification with a world community.” 22 Such a new identification could be considered the addition of a new tile to the cultural mosaic, but it could also be the simultaneous activation of multiple tiles. I would in fact assert that a global identity is both. Because it is dependent on the experience of bout with mobility or as a reaction to increased globalization, a global identity is a result of exposure to differences. Not only does that mean that the multiple identities which might have been repressed can express themselves, but also that a supra-identity can be formed based on the

\footnotetext{
${ }^{22}$ Jonas R. Kunst and David L. Sam, "Expanding the Margins of Identity: A Critique of Marginalization in a Globalized World,” in International Perspectives in Psychology, 2 (2013), 226-227.
} 
merger of those identities. ${ }^{23}$ Thus, in the acculturation process, both integration of new and old cultural identities and the adoption of a new global identity are means of increasing the breadth of the mosaic and moving toward a more complex and comprehensive form of identity.

Religion or religious affiliation is one such indicator that contributes strongly to an overarching identity like that suggested by Kunst and Sam. Rather than giving prime position to indicators like nationality, religion is in a position to transcend such boundaries, a definite plus, especially with the weakening of national boundaries in light of globalization. As Reza Aslan states in his How to Win a Cosmic War, "Now that globalization has, at the very least, begun to loosen the grip of secular nationalism on our identities, people are beginning to reassemble around older, more primal forms of identity such as religion...”24 Such a trend toward religion as a transnational identity can be seen in the umma, the global Muslim community, the focus on the solidarity of humanity among secular humanists or even atheists, or the turn to solidarity of humanity at the behest of another religious tradition like Christianity. ${ }^{25}$ This trend can also be seen in ethnonationalism, a concept that arose in response to the influence and power of “peoples” that existed between the larger nation and the smaller family unit. Ethnonationalism seeks to encompass those groups of a collective identity that exist within, across, and beyond national lines, which had once served as the basic unit of identification. (And thus conflict!) Religious ethnonationalism is a specification of the term developed to include those identity

\footnotetext{
${ }^{2323}$ See Chao and Moon, 1134-1136. Propositions 3 and 4 examine the possible reactions to negotiating multiple identities which come into contact with one another.

${ }^{24}$ Reza Aslan, How to Win a Cosmic War Reza Aslan How to Win a Cosmic War: God, Globalization, and the End of the War on Terror, (New York: Random House, 2009), 22. Aslan is, of course, not the first to make such an observation. One could also look at Held's Global Transformations, or Kunst and Sam's “Expanding the Margins of Identity" to find similar statements about the decreased relevance of national sovereignty and identity.

${ }^{25}$ See, for example, Anselm Min’s The Solidarity of Others in a Divided World, (New York: T\&T Clark International, 2004).
} 
characteristics that are based on a transcendent set of ideals and norms, and therefore another term to describe the overarching identity I have been elucidating. ${ }^{26}$

Though the effects of overarching identities prove difficult to observe from afar, especially given the variety within any such group, the true interactive results can be better understood at close range. Religious identity often involves personal struggle and questioning, and that becomes more obvious writ large if one starts at the ground level. Martin Marty uses the hurricane as metaphor for understanding these "levels of social scientific observation.” At the satellite distance, things such as identity are subsumed under the great mixture and interaction of all sorts of influences. Here modernization, secularization, racial and ethnic conflicts, nationalisms, and religion all move together into the elegant cloud swirls that mean nothing and everything. But as one gets closer to the ground level, the effects of each influencer become more apparent. In response to religion, people in their personal "huts” either batten down the hatches and weather the storm (maintaining a strong identity) or flee (sacrificing the strength of religious identity to an easier existence in the margins.) ${ }^{27}$ Religion can constrain global identity, allowing a wider reach of one particular identity indicator, but still serving to separate and distinguish those who claim that indicator from those who don't.

Thus we have the makings of religion as a strong in-group, one with whom those of other religious affiliations must interact. It is this in-group - which is so very important and salient as a personal identifier - that arises as an identity that must be protected and defended.

\section{Why is Religious Identity so Important?}

\footnotetext{
${ }^{26}$ Martin E. Marty, “The Role of Religion in Cultural Foundations of Ethnonationalism” in Religion, Ethnicity, and Self-Identity: Nations in Turmoil, Martin E. Marty and R. Scott Appleby, Eds,, (Hanover, NH: University Press of New England, 1997).

${ }^{27}$ Marty, "The Role of Religion," 6-7.
} 
Having developed an understanding of the concept of identity through culture and of religious identity as a particularly salient tile in the cultural mosaic and as an overarching identifier, I turn to the question of why such an identity is so important. Why does identity of any kind even matter?

First, identity is often a determinant of behavior, and religious identity is no exception. Aside from practices and beliefs participated in and espoused due to the relevance of religious identity, behavioral patterns such as cross-group interaction can be predicted by looking at the degree to which one identifies as personally religious or affiliated with a religious community. Such explorations of cross-group interaction have very important implications for tolerance and positive dialogue in places where multiculturalism and religious pluralism are the norm and not the exception. The point in mentioning behavior first is that it is an outward and explicit expression of identity that influences both the way people interact with each other and with the world. Thus, anything which alters, augments, or threatens that identity will affect the way a person behaves, either positively or negatively, potentially causing situations of violence and instability.

A second, possibly less readily visible reason that identity is so important is that of its influence on psychological constructs. Variations in cultural identity lead to variations in selfconstrual, which in turn is a cause of other differences in perception and, secondarily, in behavior. $^{28}$ Especially because identity is essential for self-regard and self-esteem, it is an extremely important facet to consider; if these aspects of self are affected a person's very ontological status comes into question.

\footnotetext{
${ }^{28}$ Berry, et al. Cross-Cultural Psychology: Research and Applications, $2^{\text {nd }}$ ed., (Cambridge: Cambridge University Press, 2011), 105.
} 
When talking about threats against identity, one cannot forget that the discussion is situated largely within a Western and secular context. Understanding the "self" implies a sense of individualism, a notion that the self is a concept built around a singular person and the traits exhibited by and inherent to that person. The Western view of the individual as "an independent, self-contained, autonomous entity who (a) comprises a unique configuration of internal attributes (e.g., traits, abilities, motives, and values) and (b) behaves primarily as a consequence of these internal attributes," 29 has led to the focus on interaction of individual "selves” with other individual "selves.” Rather than emphasizing the relationships between people, or focusing on the interdependence of those people, the Western conceptualization of an independent construal of the self maintains faith in "the inherent separateness of distinct persons," ${ }^{30}$ ignoring the fact that in some cultures and/or religions, such a separation is not necessarily the most desirable circumstance. One might hear the following self-centered line of thought: I am attribute X and characteristic $\mathrm{Y}$, and other individuals within the group to which I belong are also $\mathrm{X}$ and $\mathrm{Y}$, like me. This independence means that any understanding of identity is based on that same concept of autonomy and individual assertion. As such, any sort of attack on that identity is a personal one that can strongly damage a person's regard and self-valuation, without which one cannot interact with the world in a positive manner.

Alternatively, an interdependent construal of the self, more common in Eastern cultures and religions, determinedly refutes the idea of anthropologist Clifford Geertz’s (1973) "bounded" self that needs to assert and express its inner attributes. ${ }^{31}$ Rather, an interdependent

\footnotetext{
${ }^{29}$ Hazel Rose Markus and Shinobu Kitayama, "Culture and the Self: Implications for Cognition, Emotion, and Motivation,” in Psychological Review, Vol. 98, No. 2. 1991: 224-253.

${ }^{30}$ Ibid., 226.

${ }^{31}$ Geertz, Clifford, The Interpretation of Cultures: Selected Essays by Clifford Geertz, (New York: Basic Books, Inc. Publishers: 1973). “...the Western Conception of the person as a bounded, unique, more or less integrated motivational and cognitive universe, a dynamic center of awareness, emotion, judgement, and action organized into
} 
self-construal holds the self as most meaningful when it is cast in the appropriate social relationship; persons are only parts that cannot be fully understood when separated from the larger social whole. ${ }^{32}$ One might hear the following relational line of thinking: I am a mother and an employee (rather than maternal or hard-working.) A person cannot be defined without reference to another. In the interdependent self-construal, self-identity is formed more on the basis of belongingness, or affiliation with a larger group. It is not the traits of the group that the individual possesses, but the connectedness to the rest of the group whose overarching characteristics belong equally to every member. Identity attacks, therefore, are more damaging when directed toward the group rather than the individual.

Variation in self-construal - the very fact that an independent self-construal is not a necessity - means that the relevance of identity to psychological constructs and mental health might come across as suspect. If something like Geertz's bounded self, reliant upon its own inner attributes is not the norm, then it is possible that the entire discussion of identity is moot, based upon a premise that does not affect even a majority of people on earth. Though positive self-regard is often viewed as a universal need, requisite for mental health and successful interaction, it is actually rooted in Western cultural identity, where individualism and selfassertion are valued beyond anything else. In fact, "a positive self-view is not required for the construction and symbolic affirmation of the identity as an active, mutually validating and validated cultural agent" among those of an interdependent self-construal, where the self "gains meaning by being firmly suspended and supported within a web of mutually binding social

a distinctive whole and set contrastively both against other such wholes and against a social and natural background, is however incorrigible it might seem to us, a rather peculiar idea within the context of the world's cultures, (48).

${ }^{32}$ Markus and Kitayama, "Culture and the Self,” 227. 
relationships, ${ }^{33}$ Positive self-regard, then, is not a universal. One can find affirmation of existence in other ways than individual self-expression and validation. This does not, however, destroy the relevance of the identity discussion. An identity threat, even one aimed at a culture which views the self as interdependent, still carries weight; it just manifests differently. The threat may be against the relationships one maintains or against the group in which one holds membership.

Even though this thesis is limiting its scope to identities that are of Western origin, it is important to note that the issues at hand are not only Western in origin. All threats to identity can be damaging, if not in precisely the same way. The question I seek to answer is what happens when identity is threatened? What responses may be elicited? There are two very generalized possibilities. The first is that one whose identity is threatened by external forces will submit to the threats, sacrificing certain aspects of itself for peaceful coexistence. The second is that one whose identity is under threat will isolate himself, finding a way to create a safe space in which his identity is no longer threatened.

As with questioning the applicability of an identity threat to different self-construals, one could question whether an identity threat would apply to identities that center around the abnegation or effacement of self as a means to an ultimate goal. Such a concept exists in many religions: for example in the form of selfless serving in Christianity and fana or "passing away" of the self in Sufism in the search for higher knowledge and divine union. In losing one's self to gain higher understanding or reward, or in existing selflessly in order to further humanity as a whole, it may seem as though a threat to that self should perhaps only come as a further opportunity for religious gain. It is to be expected that practices like self-abnegation conflict

\footnotetext{
${ }^{33}$ Heine, Lehman, Markus, and Kitayama, “Is There a Universal Need for Positive Self-Regard?” in Psychological Review, Vol 106, No. 4, 1999. 770.
} 
with ideas of individualism, as the latter are much more recent conceptions, developed much later than the religious traditions that conflict with them. However, as with the interdependent self- construal, the problem of the self or self-identity being attacked is still as problematic: those practices or values in which one must engage or maintain in order to gain self-negation are the very things threatened.

So while it is not a direct attack on the self as a concrete person, it is an indirect attack on the overarching identity that is maintained by one who is attempting to self-abnegate. Even an understanding of identity that puts others before a sense of self, or that highlights relationships rather than attributes is still a form of identification - and one that can indeed be threatened. When religious identity is forced to take a back seat in favor of accommodative practice, it is still an attack on the way a person exists even if not directly on them individually.

In the scope of this thesis, it is the erosion of identity - whether based on a concept of independent or interdependent self - that is of concern. While both self-assertive and selfdenying identities are both subject to the possibility of erosion, it is understandable that such an erosion might come as more of a threat to one who identifies the self independently rather than interdependently.

\section{What Threatens Religious Identity?}

Now that the importance of identity has been elucidated, it is possible to approach the more difficult question of what indeed happens when it is threatened. As previously mentioned, there is a tendency toward either end of a spectrum based around giving in to the threat (accommodation) or strengthening boundaries in response to that threat (maintaining strong 
identity.) But what is it that threatens religious identity, inciting such responses in the first place?

One of the biggest factors impinging on the validity of religious identity is that of secularization. Briefly, secularization is the separation of transcendent and immanent spheres and the movement of religion to the private sphere of life. Charles Taylor describes the secular as "the "declaration of independence" of the immanent," the lower, temporal order which takes up the prime position as the real as opposed to a higher or transcendent order which becomes consigned to the position of a "human invention." ${ }^{34}$ The secular, then, is the aspect of the world that contains everything other than the arenas in which transcendent or spiritual forces hold sway. Jose Casanova describes secularization as a process, or "historical patterns of transformation and differentiation of "the religious" (ecclesiastical institutions and churches) and "the secular" (state, economy, science, art, entertainment, health and welfare, etc.) institutional spheres from early modern to contemporary societies.” ${ }^{35}$ Secularization is the process of differentiating those institutions which profess some sort of higher power or order from those which don't, making more explicit the dynamic and dependent relation between the two.

Joseph B. Tamney and Stephen D. Johnson found in a study carried out in 1985 that religious influence declines in the shift from family to work to politics, ${ }^{36}$ showing that secularization has indeed been successful. In the same way that religious influence increases from a satellite view of social interaction to an on-the-ground view of individual interaction, so too it increases in the movement from the public to the private spheres. This is the result of the secularization of society, the separation of spheres made possible by a change in self-

\footnotetext{
${ }^{34}$ Charles Taylor, "Western Secularity,” in Rethinking Secularism, ed. Craig Calhoun, et al., (Oxford: Oxford University Press, 2011), 33.

${ }^{35}$ Jose Casanova, "The Secular, Secularizations, and Secularisms," in Rethinking Secularism., 33.

${ }^{36}$ Joseph B. Tamney and Stephen D. Johnson, "Consequential Religiosity in Modern Society," in Review of Religious Research, Vol. 26, No. 4, June 1985, 365.
} 
understanding. From an earlier comprehension of the world, one which was "enchanted," to use Charles Taylor's expression, full of spirits and forces from which people had no separation, we as a people moved to a more modern understanding, one in which we "buffered" ourselves from these forces and spirits, disengaging from them and separating ourselves. ${ }^{37}$ Such a change from a "porous" self to a "buffered self" led to a world where divine intervention and the religious authority built from revelation could be relegated to a private sphere, influential only in family or personal matters, but not the concern of the everyday secular, temporal, real world.

In Western modernity, where Taylor’s "buffered self” reigns supreme, secularization is often assumed necessary for the successful implementation of any government or institution with a diverse constituency. ${ }^{38}$ However, religion remains important to many and thus the privatization of religion is necessary to ensure that it won't become a totally divisive and conflict-inducing issue. Since the 1648 Peace of Westphalia, which established the sovereignty of the nation-state, subjecting religion and religious authority to the nation, religion has, in a Western context, become the diminished institution often treasured as a relic of the past or thrown aside in favor of fresh, modern updates. With such an understanding, religion, it seems, has no place but the private realm. In fact, says Casanova, "modern secularization entails a certain profanation of religion through its privatization and individualization and a certain sacralization of the secular spheres of politics (sacred nation, sacred citizenship, sacred constitution), science (temples of knowledge), and economics (through commodity fetishism).”39 Not only is religion marginalized, but it is reduced in comparison with highly lauded secular institutions which are recognized as vastly more important and integral to overall identity (which

\footnotetext{
${ }^{37}$ Taylor, "Western Secularity," 41.

${ }^{38}$ This, of course, is not true in every case, as there are some governments that allow religion to have some kind of role in the public eye. An example would be states which have institutionalized religious tradition, Islamic states coming immediately to mind, where Shari'a as well as secular law is codified.

${ }^{39}$ Casanova, 65.
} 
is often assumed to be based solely on nationality.) One result of religion's precarious position because of secularization has been the development of a fundamentalist identity, one which fears the total eradication of a key part of both lifestyle and personal formation. I shall return to this idea shortly.

Secularism manifests in several different ways, but in all its formats it ostensibly proposes to maintain the equal rights to the practice of religion or beliefs, whether philosophical or transcendent; the separation of spheres into public and private is supposedly a way of protecting the institution of religion and its expression by equalizing it with other institutions, thus preventing any preference or establishment of any one religion over others. ${ }^{40}$

That premise, however, is interpreted and carried out differently in various places. In the United States, where the disestablishment clause of the constitution ("Congress shall make no law respecting an establishment of religion, or prohibiting the free exercise thereof...”) prevents the government from favoring one religion over another or making religious adherence compulsory, secularism serves to separate but not remove religion from the public arena. The American ideal of secularism with regards to religion, then, is to promote the free practice of religion without compelling any one religious practice: freedom of religion. In India, secularism is often rendered as "Dharma Nirapekshata," in Hindi and other vernacular languages; this approximately means “religious neutrality.” Religious neutrality seems most frequently to manifest in equal opportunity support of every religious group represented in the Indian state: this is secularism as freedom for religion. Secularism in France, or laïcité, to be somwhat

\footnotetext{
${ }^{40}$ In contradiction to this, one might point to China, where secularization has led to a separation so strong that religion has effectively been banned. This comes out of a historical battle over the access to transcendence (even if not monotheistic in tradition), where banning religious groups makes the question of state-controlled transcendence moot. Thus, Chinese secularism is also inherently rooted in the need to protect public access to transcendence, rather than any flagrant decision to remove religion from the world. Prasenjit Duara, "The Historical Roots and Character of Secularism in China” in The Newsletter, Issue 54, Summer 2010, International Institute for Asian Studies. http://www.iias.nl/the-newsletter/article/historical-roots-and-character-secularism-china
} 
reductionist, makes certain the public and private spheres are kept completely separate, so that any religious practice is expressed by an individual and not endorsed or compelled by the Republic. Talal Asad explains that the French Republic operates under the principle that "the religion of the ruler is the religion of his subjects” by installing the sovereign state as an absolute power that does not commit to a particular religion. It is, therefore, the task of the state to care for the population "regardless of its beliefs." 41 To this end, the state exercises its sovereign power to "dominate public space as the space of particular [religious] signs" 42 (such as the hijab, the Islamic veil.) In French secularism, the state determines what is acceptable for public display or expression, not as an attempt at repression of religion in total, but an attempt to place religion in its rightful position in the private realm. This has led to French secularism being seen as an attempt at the removal and reduction of religion from the public, freedom from religion at its strongest.

These are only three manifestations of secularism among potentially countless others. Although secularization purports to maintain the equal right of all to practice religion, it can often come across as oppositional to it, since so much prevalence is given to the public sphere over the private one. By emphasizing the immanent over the transcendent (as per Charles Taylor), religion is given a second-class status, not as real as the important institutions (like the state and economics) that are maintained in the public arena. To someone who identifies themselves largely through their religion, religious affiliation, or belief systems, such a demotion is quite detrimental. If one's religion tile within their identity mosaic is particularly large and high up in the hierarchy, then any threat against it has deleterious ramifications for their whole being. Especially because religion is so ubiquitous in a person's life - it is a code for living, a

\footnotetext{
${ }^{41}$ Talal Asad, "French Secularism and the "Islamic Veil Affair,"” in The Hedgehog Review, Spring \& Summer 2006, 94.

${ }^{42}$ Asad, 101, emphasis mine.
} 
world-view - the movement of any required or recommended practices to the private sphere prevents one from engaging fully in the convictions and values which guide one's life. For a person of such convictions, this is unacceptable.

A second factor threatening religious identity is the practice of interfaith or interreligious dialogue. Though it may seem a wholly beneficial practice on the outside, the methodology employed in its practice can be as detrimental to religious identity as an outright prejudiced attack. It is especially the practice of accommodation - relinquishing some aspects of religious identity in order to emphasize similarities and get along more smoothly - which diminishes identity. Chapter two will go into more detail on this problem. Chapter three will explore further some institutionalized attempts at interfaith interaction, carefully observing and critiquing the successes and failures of each.

One of the end-goals of interfaith dialogue is to reduce the intolerance and prejudice running rampant among peoples of different religions. The social identity complexity theory is here particularly germane: multiple group membership translates to a higher identity complexity and a reduced motivation for in-group bias. ${ }^{43}$ This reduction of out-group intolerance is bolstered by the fact that with everyone’s identity being so complex, no single aspect of identity is the ultimate determinant of a person's overall conception of self or belongingness. A cultural mosaic identity is one of total complexity, with multiple in-groups leading to the promotion of interaction with out-groups, who are not seen as irreconcilably different in light of one’s various reconciled affiliations.

Theoretically, even the simple exposure to different religions ought to help in the reduction of out-group intolerance and therefore the threat to religious identity, but the process is far more complex. Although conversation, interaction, and trust-building are often part of

\footnotetext{
${ }^{43}$ Brewer and Pierce "Identity Complexity," 431.
} 
interfaith dialogue, these activities tend to focus on commonalities, ignoring differences for the sake of getting along peacefully. A "common ground" approach is not a negative one unless it stops at similarities, fearing to broach the topic of reconcilable or irreconcilable differences. By ignoring such unique aspects of peoples' religious identities, those identities are reduced, trimmed by sacrifice for what is supposedly the greater good.

For those who maintain a strong religious identity, what then are some of the responses to these threats made manifest in a deliberate reduction in religion's area of effectiveness (secularization) and in common ground approaches to interfaith dialogue?

One of the first and most widely recognized and feared responses is that of religious fundamentalism. Although fundamentalist as a term has been used to describe countless different groups with a varying degree of accuracy, it is a challenge to pin down any one particular definition. Here I will follow the excellent treatment on the characteristics of fundamentalism espoused by Gabriel A. Almond, R. Scott Appleby, and Emmanuel Sivan in their cooperative work, Strong Religion. In chapter two, nine traits - five ideological and four organizational - are laid out to form a baseline of family resemblances among fundamentalist groups. The ideological traits include reactivity, selectivity, moral Manichaeism (dualism), absolutism and inerrancy, and millennialism and messianism. The organizational traits are an elect, chosen membership, sharp boundaries, authoritarian organization, and strict behavioral requirements. ${ }^{44}$ Though groups marked as fundamentalists by out-group members have unique characteristics and are certainly not uniform across the board, these traits serve as a way to identify a decidedly fundamentalist mode of being.

\footnotetext{
${ }^{44}$ Gabriel A. Almond, R. Scott Appleby, and Emmanuel Sivan, Strong Religion: The Rise of Fundamentalisms around the World, (Chicago: University of Chicago Press, 2003), Chapter 2.
} 
The most important of these traits is the first. Reactivity lays the groundwork for the fundamentalist identity, because without reacting to something, sparking a behavioral or ideological change, no new identity needs to develop. For fundamentalists, whose cultural mosaic sports a religion tile disproportionately larger than other identifying tiles, reacting to the perceived marginalization of religion is the cornerstone in a new foundational set of beliefs and values that sort themselves into the other eight traits previously described - most especially the tendency toward sharp boundaries and a withdrawal from the non-select within the world. It is the refusal to be drawn into a secularized state wherein they are unable to give religion the full scope it deserves. In Tamney and Johnson’s 1985 study on the measure of religious influence, only those who identified as fundamentalists claimed religious influence in all three areas tested: family life, work, and politics. ${ }^{45}$ With religion influencing every part of a fundamentalist's life, it is no struggle to see why the perceived attack on religion by the nation-state or by secularized institutions is so traumatic. It is essentially the destruction of a large and important part of the way a fundamentalist self-identifies. One can imagine them saying, "if you take away my religion, what do I have left?” The fundamentalist identity, then, is one under constant threat. ${ }^{46}$ Another potential response to identity threats, rather than staunchly reacting with isolation and increased boundaries, is that of what I would like to call religious convictionism. A convictionist is one who holds on strongly to her beliefs, but feels no compulsion to do so within an enclave. The term differs from the general noun "conviction,” which is a firm belief; convictionism, on the other hand, is a centering of one's life in some way around such a belief. Convictionism is a degreed term, relative to the previously defined fundamentalism, which is at the extreme end of the religious identity spectrum. Convictionists live in the gray area of “I’m

\footnotetext{
${ }^{45}$ Tamney and Johnson, “Consequential Religiosity,” 369.

${ }^{46}$ For a further elaboration of this concept, see “The Enclave Culture,” Chapter 1 in Strong Religion.
} 
religious but not one of those fundamentalists," where secularism does not threaten religious identity, and the confrontation with a pluralist society does not mean that irreconcilable differences must frighten us. Similar to, but perhaps a degree more intense than, this term is that of R. Scott Appleby’s “militants,” those who “"'go to extremes” of self-sacrifice in devotion to the sacred.” ${ }^{47}$ Being a militant does not require either the violence popularly associated with fundamentalist reactions or the strict boundaries of differentiation - it merely requires the conviction of strong religious beliefs and the understanding that those beliefs affect every aspect of life. Appleby adds that militants can be both "peacemakers" and "extremists," acting in response to their beliefs in a positive or negative manner, respectively. ${ }^{48}$ Militance, then is perhaps one level above convictionism, but one below fundamentalism in the spectrum of maintaining religious identity. Though both militants and convictionists maintain religious identities within a secularized, pluralist context, militants are more reactive. A convictionist as I am attempting to define, lives everyday life within the directives of his religion, accommodating only to the point of balancing the separate private and public spheres.

Convictionism, religious militancy, and fundamentalism show that religious identity can indeed be maintained in light of the threats posed by secularization and the pluralist context underlying interfaith work. Though they all respond differently, they are all indeed responses and unsurprising ones at that. Charles Liebman, in fact, argues that what he calls "extremism" is actually the norm for religious practice; it is the tendency toward religions moderation and the accommodationist practices that inform where people land in the religious identity hierarchy which requires explanation. For Liebman, extremism is defined through three dimensions: expansion of religious law, social isolation, and cultural rejection. These characteristics share

\footnotetext{
${ }^{47}$ R. Scott Appleby, The Ambivalence of the Sacred, 11.

${ }^{48}$ Ibid.
} 
some features of Strong Religion's definition of fundamentalism, but because Liebman’s extremism is "an ideal typical impulse" 49 rather than an actualized phenomenon, it can be understood as distinct. It is, perhaps, a generalizable form of expressing strong religious conviction. This extremism is reactionary to its surroundings and actually comes about as a result of them.

Religious extremism assumes a very high level of religious differentiation. Extremism is restrained when religion is an organic part of the society diffused throughout its institutions. Where differentiation has taken place, the religious institution is often impelled to worldly activity in order to maximize its autonomy, control its environment, protect itself, attract adherents, etc. The need for the approval of others and the interaction with other economic and political institutions introduces a compromising or adaptationist tendency. ${ }^{50}$

By keeping religion from being diffused throughout all of society, secularization can actually encourage devotion and increased adherence in order to ensure it is maintained even when restricted from holding supreme authority. That those who wish to stand strong against accommodative practices eroding their religious identity is, actually, to be expected. Defining a new term within the spectrum of strong identity maintainers is particularly important within the scope of this thesis because the majority of people involved in the very circumstance ultimately under consideration - interfaith movements - exist as relatively non-reactive people of strong conviction who work within the secularized world to build relationships with other equally convicted people. As a response to the threat of identity incurred in the confrontation with pluralism, convictionism is impossible to ignore.

\footnotetext{
${ }^{49}$ Charles Liebman, "Extremism as a Religious Norm," in Journal for the Scientific Study of Religion, Vol.22, No. 1, Mar. 1983), 77.

${ }^{50}$ Ibid., 79.
} 
Identity itself is a difficult concept to encapsulate, and approaching it as complex, malleable, and determined by the interaction of its composite parts is a helpful way to begin that process. That cultural identity and within that religious identity serve to inspire and regulate behavioral patterns and interaction as well as psychological constructs like cognition and emotion mean that any threat to that identity is actually a threat to the very way a person exists in the world. Responses to the threat of the erosion of identity are therefore not surprising, even when some of those responses are negative. Having looked at the nature and salience of identity, the threats to it, and the resulting responses, I can now turn to an exploration of the context in which these identity groups exist. 
Chapter 2:

The Assumption of Pluralism and its Philosophical and Theological Models

It would be a fool's errand to dispute the existence of differences within humanity. It is the existence of such difference which has fascinated explorers, anthropologists, philosophers, and theologians for centuries. Of course, the ways in which those differences are approached is most certainly not uniform across the board. Within this thesis, I am focusing specifically on religious differences, or the circumstance of religious pluralism. Diana Eck, who has been a champion of pluralism, especially in her work on the Pluralism Project through Harvard University, defines pluralism as an achievement rather than a given.

First, pluralism is not diversity alone, but the energetic engagement with diversity. [...] Second, pluralism is not just tolerance, but the active seeking of understanding across lines of difference. [...] Third, pluralism is not relativism, but the encounter of commitments. [...] Fourth, pluralism is based on dialogue. The language of pluralism is that of dialogue and encounter, give and take, criticism and self-criticism. Dialogue means both speaking and listening, and that process reveals both common understandings and real differences. Dialogue does not mean everyone at the "table” will agree with one another. Pluralism involves the commitment to being at the table -- with one's commitments. ${ }^{51}$ I strongly support and applaud Eck’s encouragement of action accompanying the circumstance of diversity, though I don't believe the two together constitute pluralism itself. Rather, what she describes is the process of interfaith dialogue, which comes out of the existential reality of pluralism. What Eck merely labels diversity or difference is what I call pluralism. The existence of and confrontation with diversity requires conversation and understanding in order for anything resembling peaceful coexistence to come about. Though Eck uplifts pluralism as the pinnacle of the results of such conversation, it is in fact the foundation for that conversation to take place.

${ }^{51}$ Diana L. Eck, “What is Pluralism?” The Pluralism Project: Harvard University, pluralism.org 
A more solid understanding of the phenomenon of pluralism is in order, and is the concern of the first part of this chapter. I will discuss this phenomenon, moving from a descriptive and relativized understanding of the concept to one rooted in ontology itself. In the second part of the chapter, I will elucidate two different approaches to interfaith interaction spawned by an acceptance of the pluralist status of the world. In the final part of the chapter, I will tie the philosophical and theological approaches to interfaith work back to the identity discussion of the first chapter, exploring the benefits and drawbacks of different models for the maintenance of identity in light of interfaith interaction.

\section{On Pluralism}

Diana Eck’s pluralism understood as an end rather than as a descriptive circumstance seems to me somewhat naïve. I would love to see a world where diversity implied open dialogue and frank discussion, but I fear we are not quite there yet. Instead, we are faced with a situation of diversity and differences that are often incommensurable. Those incommensurable differences are a fact, and not merely a matter of perspective. It is from an awareness of such differences that dialogue must begin. Raimon Panikkar's understanding of pluralism comes from such awareness. "Pluralism stands between unrelated plurality and a monolithic unity. It implies that the human condition in its present reality should not be neglected, let alone despised in favor of an ideal (?) situation of human uniformity. On the contrary, it takes our factual situation as real and affirms that in the actual polarities of our human existence we find our real being." 52 More recently, he states: "Pluralism is inherent to the human condition and prevents us from speaking of God by starting from a single perspective or a unique principle of

\footnotetext{
${ }^{52}$ Raimon Panikkar, The Intrareligious Dialogue, (New York: Paulist Press, 1978), xxvii-xxviii.
} 
intelligibility...Every claim to reduce the symbol God to what we understand by that symbol not only would destroy the symbol but also would cut our links with all those peoples and cultures that do not feel the necessity of that symbol." ${ }^{\text {53 }}$ For Panikkar, irreconcilability is at the very core of human understanding; a movement toward uniformity or toward an understanding which seeks to utilize the same language does not do justice to the situation at hand. He advocates an “ontological pluralism,” which Anselm Min, in an analysis of Panikkar’s ideology, describes as "empower[ing] the harmony or solidarity of those who are irreducible different." ${ }^{\text {} 54}$ Ontological pluralism, then, is one in which incommensurable differences do not have to be wholly understood, but must still be transcended. The tendency toward one end of the spectrum of understanding - toward intellectualism and reducing everything to truth claims - has to be overcome in favor of realizing the situation on the ground: "truth is pluralistic, neither one nor many,"55 Only then can any further action be taken that moves toward dialogue and then the sort of idealized condition Diana Eck imagines in her definition of pluralism.

Ontological pluralism is not solely the brainchild of Panikkar and Min. It is also endorsed by philosopher DZ Phillips, though in his case he labels it "radical pluralism.” This concept is distinct from the theological perspectives of inclusivism (one religion encompasses the truth of all others) and exclusivism (only one religion is true). Phillips differentiates radical pluralism even from (theological) pluralism, which comprehends that no one religion has a complete revelation of the divine or that the divine can be known only through a synthesis of the values of each religion. Phillips' use of the fourth category of radical pluralism comes largely out of his Wittgensteinian philosophy of understanding religion grammatically, analyzing beliefs

\footnotetext{
${ }^{53}$ Raimon Panikkar, The Experience of God: Icons of the Mystery, (Minneapolis: Augsburg Fortress, 2006$), 19$.

${ }^{54}$ Anselm Min, “Loving without Understanding: Raimon Panikkar’s ontological pluralism," International Journal for Philosophy of Religion 68 (2010): 63.

${ }^{55}$ Ibid., 65.
} 
through their meaning, a process rendered nearly impossible by the instability of meaning and challenge of language. In the same way that language and discourse is impossible to reduce to a single characteristic, religions exist in relation to each other through a series of family resemblances - different cords tying them to one another without one large cord linking them all. Radical pluralism allows one to see and contemplate these relations without succumbing to the desire of some critics of the grammatical approach to ordain for them common criteria of rationality or external justification for their values. ${ }^{56}$ (Both of these problems can be found in the pluralism of John Hick, to whom I turn below.) In the same way that Min’s ontological pluralism recognizes the inherent plurality of being, the philosophical contemplation inherent in Phillips' radical pluralism “endeavors to let the world be itself in all its variety. It allows the hubbub of voices and their diverse relations to each other to be themselves.” 57 Both conceptions of pluralism allow for the fact that the total reconciliation of diverse religious traditions might not be a possibility, but that such reconciliation is not the end-goal. Rather, it is the recognition of differences and contemplation of how those differences can be addressed or understood that are at the heart of both radical and ontological pluralism. Phillips' radical pluralism does not necessarily encourage dialogue, as it is a philosophical conception of the state of things, attempting to contemplate not only conflicts and disagreements, but also the reality that there are those who refuse to engage to create such conflicts in the first place. It still stands, however, that beginning with a philosophical conception of inherent plurality (radical pluralism) or a

\footnotetext{
${ }^{56}$ D.Z. Phillips, "Religious Beliefs and Language Games,” Wittgenstein and Religion, (London: The Macmillan Press LTD, 1993), 56-57. This chapter explains misgivings felt by those labeling religious beliefs language games: that such a conception renders religious beliefs either insignificant outside those who understand and are indoctrinated in the language (religion) under question, and that categorizing religious beliefs as language games moves them beyond the reach of criticism, being on logically uncommon ground.

${ }^{57}$ D.Z. Phillips, "Philosophy's Radical Pluralism in the House of Intellect - A Reply to Henk Vroom,” D.Z. Phillips' Contemplative Philosophy of Religion: Questions and Responses, ed. Andy F. Sanders, (Abingdon: Ashgate Publishing Group, 2007), 205.
} 
theological conception of pluralism as a state of being (ontological pluralism) both increase the very possibility of dialogue.

By admitting pluralism only in the context of incomplete perspectives or variations on one single transcendent ideal, we are naturally limited as to the end goal: success means only conversion or persuasion. But in accepting an ontological or radical pluralism, we recognize that contemplation, conversation, and dialogue are themselves end-goals. They may be open to disagreement or agreement, but mostly they are open. Through ontological or radical pluralism, in recognizing the inherence of plurality to our very being, we can begin approaching our differences as mystery rather than as problems to be solved. Min states, "In radically relativizing and transcending the category of the intellect to the irreducible pluralism of being itself, ontological pluralism frees us from the obsession with intellectual agreement or lack of agreement, and allows us to love one another despite our intellectual differences, even despite our inability to understand one another, and even when we do not love the same things." ${ }^{58}$ By recognizing pluralism as the natural state of things, we can move toward dialogue that accepts and loves despite differences, without understanding them.

In accepting ontological and radical pluralism as a foundation for understanding the religious diversity of the world, it must still be acknowledged that happy loving dialogue will not simply magically occur. Multiple truth claims will come into confrontation in such dialogue and with those conflicting claims will arise varied responses. One might refuse to acknowledge any other religions as correct or valid, thus giving in to the call of exclusivism. There might be conversion attempts in which one person tries to bring another around to sharing their beliefs. One might be merely “tolerant,” meaning he grudgingly allows that those of other religions, while incorrect or misguided, must still inhabit the same world. There are those who will remain

\footnotetext{
${ }^{58}$ Min, “Loving Without Understanding,” 70.
} 
indifferent, making neither positive nor negative effort toward others of different religions. There might be a sort of universal acceptance of difference, claiming an ultimate reality that encompasses all. And finally, there might be a desire for true dialogue and mutual learning and teaching, in which people come together to embrace their differences and still coexist.

All such reactions are acknowledged within radical pluralism, as it contemplates all states of comprehending the world, from a single-minded approach to belief systems all the way to a wide ranging universalism. It also acknowledges the mutual exchange of religious influence as well as the destruction or creation of religious allegiance in a person's life. ${ }^{59}$ Dialogue is therefore a possibility within radical pluralism, but it is not the necessary outcome. Ontological pluralism, however, as a theological approach, does indeed hope for a positive relational endgoal. It recognizes difference and even affirms it, but it also recognizes the need for discussion and understanding of those differences for fruitful coexistence. It is this for which we, like Diana Eck in her idealized pluralist society, ultimately hope. Ontological pluralism, then, is the strongest foundation from which interfaith dialogue must be launched.

\section{On Interfaith Dialogue}

Interfaith dialogue is a practice of engaging in conversation with another person with an ultimate end goal of understanding, relationship, and respect. It is a particularly helpful course of action if we wish to avoid the "clash of civilizations" ${ }^{60}$ made inevitable by irreconcilable differences. Though it seems on the surface to be a largely benevolent and beneficial interaction, interfaith dialogue has the potential for deleterious results. Some possibilities (exclusivism,

\footnotetext{
${ }^{59}$ Phillips, "Philosophy's Radical Pluralism,” 205-210.

${ }^{60}$ Samuel P. Huntington, The Clash of Civilizations and the Remaking of World Order, (New York: Touchstone, 1997)
} 
conversion, or mere tolerance) pose a threat against a person's religious identity in explicitly denying the validity of her religion. Interfaith dialogue poses a threat to that religious identity implicitly, in the form of faulty methodology that can lead to the ignoring and thus erosion of unique differences.

In general, the methodology accompanying an acceptance of pluralism and a movement toward interfaith interaction manifests in two ways. In the first (identity-threatening) method, one emphasizes similarities over differences, leading toward the same accommodative practices that sparked fundamentalists into intense reaction. In the second, difference is emphasized over similarity. By honoring difference, this methodology allows for true acceptance of all religions, though disagreement is expected - and welcomed - because of irreconcilable differences.

Naturally, there are problems with both approaches, and they will be addressed in turn.

The first methodology, which emphasizes similarities over differences, is what I term a “common ground” approach and can be represented by the universalism of John Hick.

Borrowing heavily from Kant’s epistemology, Hick observes the dichotomous relationship between the noumenon and the phenomenon, or between the thing as is and as it appears to us. This distinction he applies to religion, faith, and conceptions of the divine, saying:

“...the noumenal Real is experienced and thought by different human mentalitites, forming and formed by different religious traditions, as the range of gods and absolutes which the phenomenology of religion reports. And these divine personae and metaphysical impersonae, as I shall call them, are not illusory, but are empirically, that is experientially, real as authentic manifestations of the Real." 61

While Kant denies that the noumenal can ever be fully experienced, Hick insists that the human condition mediates this experience, presenting us with the various interpretations of the divine

${ }^{61}$ John Hick, An Interpretation of Religion: Human Responses to the Transcendent, Second Edition, (New Haven: Yale University Press, 2004), 241. 
which are present today in the multiplicity of religions, beliefs, and philosophical systems. The common ground, therefore is that all religions are striving for an understanding or interpretation of the same ultimate Real, something above and beyond any one interpretation. It is this ultimate Real that allows for any work on comparative religions to be done and this ultimate Real which also serves as a criterion for judging or grading the various interpretations (religions). ${ }^{62}$

Hick's understanding of pluralism, then, is decidedly not ontological or radical, as it rests on the assumption that there is a greater reality than that in which the multiplicity of religions resides. The true and actual situation is the noumenal one, and plurality only comes as a means of interpreting that situation. When dialogue occurs, it is on the premise that there is a shared ultimate goal, that every difference is merely a way of expressing the same thing, individualized by context - space and time create the diversity in interpretation.

Hick's pluralism is problematic. The ultimate Real, while creating room for the parity of all interpretations, stands itself as another interpretation in a long line of them. Every religion must then be wrong in thinking it is the only or truest way of experiencing the divine. Phillip Quinn, when discussing Hick himself, aptly notes that Hick’s hypothesis "attributes large errors” to many members of various traditions. Those who, like Christians, believe that the Real is personal must fight with those who, like Buddhists, believe in the impersonal nature of the Real. All Hick can say here is that the noumenal Real is neither personal nor impersonal; he must offer another interpretation. The problem, then, is that this pluralist hypothesis emphasizes universalism or unity rather than pluralism. He is actually something of an inclusivist, inviting all to participate in his understanding that there is only one singular noumenal Real. Though the means of experiencing it are diverse, the knowledge that there is only one ought to be universal. While this seems at the outset to give credence to the various traditions, it becomes problematic:

62 John Hick, Problems of Religious Pluralism, (New York: St. Martin’s Press, 1985), 68-69. 
who wishes to be told that their unique approach to religious interpretation is actually the same as or just a minor variation of a group with whom they have been fighting for centuries? Assuming the end goal is the same requires that some traditions (or indeed all traditions!) must change to achieve it.

In contrast to John Hick is a model of pluralism that Paul Knitter calls "The Acceptance Model” in his book Introducing Theologies of Religions. This model is predicated on an ontological pluralism. In a one-line summary of the model, Knitter elaborates, "the religious traditions of the world are really different, and we have to accept those differences." ${ }^{63}$ This is quite different from Hick's claim for the acceptance of diversity, for Hick accepts it only inasmuch as it is a plurality of interpretations of one ultimate Real. The acceptance model, on the other hand, understands that there could be many Reals. S. Mark Heim's model is representative of this ideology, as exemplified in his book Salvations: Truth and Difference in Religion. Heim's model indeed accepts pluralism in the ontological sense, as a reality within which we must work to reconcile irreconcilable differences. The largest distinction from Hick's pluralism is that Heim's model does not accept that there is only one ultimate Real. In fact, says Heim, "it could also be that there are in fact various realities in the noumenal realm which are religiously significant and which ground diverse religious fulfillments (for instance, both some form of personal deity and a condition similar to that described as nirvana)." ${ }^{94}$ There are thus "an open set of varied religious ends" ${ }^{\prime 5}$ which could be realized, some which might share historical or eschatological features, and some which might not.

The open-endedness of Heim's model means that people of different religions are not competing for a single ultimate reality. It is much easier to have discussion when your

\footnotetext{
${ }^{63}$ Paul Knitter, Introducing Theologies of Religions, (New York: Maryknoll, 2002), 173.

${ }^{64}$ S. Mark Heim, Salvations: Truth and Difference in Religion, (New York, Maryknoll, 1995), 146. ${ }^{65}$ Ibid.
} 
eschatological position doesn’t depend upon convincing someone else you are correct. If I as a Christian am talking about salvation with you, a Buddhist, there is no need for persuasion or angry conversion because both our ultimate goals, even our ultimate conceptions of the transcendent, are both valid. In a statement that is sure to leave some people gobsmacked, Heim says, "Nirvana and communion with God are contradictory only if we assume that one or the other must be the sole fate for all human beings. True, they cannot both be true at the same time of the same person. But for different people, or the same person at different times, there is no necessary contradiction in both being true.. ${ }^{, 66}$ Dialogue is therefore not a means to some sort of unification or consensus, but an end in itself. Dialogue and open conversation with mutual teaching and learning is thus the successful employment of Heim's model, leading to a (hopefully) happier existence.

Though I prefer Heim's model to Hick's, I still find some problems within it. The first is that it seems to accept too much. If everything is true, what then is to be said of religious systems which are logically inconsistent with one another? Heim answers this objection by stating carefully that "it is important to recognize that the hypothesis affirms the reality of different experiential states of religious fulfillment; it does not require that all of the elements a tradition associates with attainment of that state are also the case.”67 In other words, Heim is dissociating the human traditions developed with attaining an end-goal from the end-goal itself. I am not entirely convinced by his argument, as such wording seems to imply that religions are only as important as the transcendent elements within them, leaving all other aspects to the side. This is problematic since the traditional systematic aspects of religion make up much of what guides a person in her life. What would Islam be without Shari'a? Where would Christianity be

\footnotetext{
${ }^{66}$ Ibid., 149.

${ }^{67}$ Ibid., 154.
} 
without the practical application of Christ's teachings in everyday life? I respond that the acceptance model must accept both ends and means equally. If we can grasp the incommensurability and validity of an ultimate end of a religion, then surely the different means which are equipped for attaining those ends can be respected and appreciated within their own realities.

The second objection I raise has to do with the privileging of certain religions over others. Though Heim does not at all argue for some kind of overall graded order of religions, the fact still remains that we maintain our religions because we think that they are better than others. Perhaps better is not quite fair - but at least we believe that the religion we hold dear has something that others don't: why else would we practice it? The fact of the matter is the acceptance model requires a certain tension between the validity of all religious realities and the privileging of our own faith. Heim answers this objection by explaining he wouldn't want a model that negated the "human capacity to seek differing religious fulfillments." 68 The convictions that any religious adherent feels cannot be removed unless the entire notion of pluralism is itself removed. I think this response is quite fair!

The other aspect of the issue of privileging language lies in Heim's use of language rooted in Christian theology to describe his model. Talking about salvations is quite different than the usual Christian expression of what salvation means (as possible only through Christ), but even using that term makes certain assumptions about what the ultimate end-goals might look like. Heim describes later what he really means by using the term "salvations" as synonymous with end-goals. “"Salvation” or religious fulfillment for any religious community is integrally related to a comprehensive pattern of life. Any particular religious tradition would regard someone as "saved" whose life had been most fully shaped by the distinctive pattern is

\footnotetext{
${ }^{68}$ Heim, Salvations, 154.
} 
fosters." ${ }^{69}$ Simply couching his model in the terms of the tradition in which he hails is hardly a crime or indeed a mark against him. But it is something we must be careful of doing, or the privileging of one religion over another leads to inclusivism, similar to the threat of homogenization of cultures and identities looming in the globalization process. As we become more interconnected, are we creating a new supra-identity or are we merely all being merged into Western ideals? The same issue arises in the use of particular terminology when referring to an overarching concept.

Another interesting approach to pluralism that suffers the same linguistic privileging problem as Heim’s “salvations” is Anselm Min’s concept of solidarity and dignity. For Min, within inherent (ontological) pluralism, we need a strong unifying factor - a global theology - to bind us together in a "coherence among the different." ${ }^{70}$ He roots this binding in the concept of human dignity and solidarity, both of which are based on the universal of human nature.

Because we are all human, we all have worth, and it is in coming together interdependently that the "solidarity of others" is expressed. "Solidarity of others," Min explains, "implies that there is no privileged perspective, that all are others to one another, that we as others to one another are

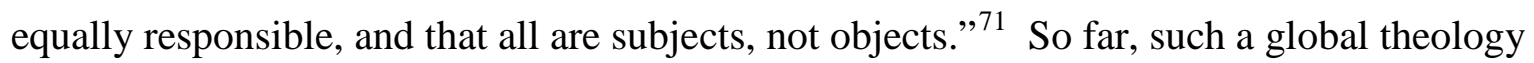
seems perfectly in line with Heim's model, in that it accepts differences willingly. It does, however, start to bring in something of universalism by locating the value of humanity in something beyond any particular manifestation of that universal. Min then locates the whole theology in a Christian perspective. Ultimately, the value inherent in human nature is not something in the noumenal Real or in each unique Real. Rather, it is in the fact that all humans, along with all other beings are creatures, from the Creator. The ultimate exemplar of this

\footnotetext{
${ }^{69}$ Heim, Salvations, 162.

${ }^{70}$ Anselm Min, The Solidarity of Others in a Divided World, (New York: T\&T Clark International, 2004$), 66$.

${ }^{71}$ Ibid., 82.
} 
solidarity can in fact be found in the Triune God, who is interdependence and solidarity beyond anything mere humans can hope to achieve. ${ }^{72}$ Because Min acknowledges immediately that he is working from a Christian perspective, I cannot fault him too terribly for using Christian language and symbolism to delineate his theology. However, there still remains the fact that in saying something as essential as human nature and interdependence come from God, and the Christian understanding of God at that, that he is privileging Christianity above other religious traditions. Heim combatted this issue by explaining that the tension will always exist between acceptance of all religions and the participation in one. Min does something similar:

“...Pluralism does not entail reducing every distinctive belief to a common denominator or speaking from a neutral, universal perspective - which is precisely the opposite of pluralism. What it does entail is thinking hard through one's own position with what I called the heterological imperative, exploring within the best and deepest of one's own tradition the possibility of making room for the other, and exposing oneself to the dialectic of dialogue and interaction with the other."73

Privileging one's own tradition in explaining it to others is no real evil unless one makes no room for the same privileged voices of others. I am a Christian, and understand the world through a Christian lens; what other choice do I have but to couch things in terms that first make sense to me before beginning the process of translation?

We are reminded once again of language and discourse (and religion!) as a set of family resemblances: a direct translation from one to all others is impossible, because there is no unifying thread linking them all. Rather, such translation must happen from one language (religion) to another, individually until multiple understandings have been achieved by multiple means.

\footnotetext{
${ }^{72}$ Min, Solidarity of Others, 82-87.

${ }^{73}$ Ibid. 86.
} 
Thus, the issue of privileging one’s own tradition isn't really an objection to an ontological model of pluralism at all, unless one refuses to listen to the privileged language of another and therefore fails to glean anything from it. ${ }^{74}$ The fundamentalists referred to in Chapter 1 fit this category, reacting strongly to the possibility that their perspective is endangered by other religious realities. While they are less likely to engage in the sort of dialogue under discussion here, they are also unlikely to accept anything like ontological pluralism, and so the concern is not particularly relevant. Believers who are willing to engage in dialogue, therefore, are those who are grounded in the first place in ontological pluralism.

Before turning to a final section regarding the impact of these models on the mosaic identity unraveled in Chapter 1, I want to look at one more model of pluralism, which was developed after examining both Hick's and Heim's models. Yong Huang, in his article "Religious Pluralism and Interfaith Dialogue: Beyond Universalism and Particularism,” brings to our attention a model which "interprets religious plurality not through metaphysical mediation about transcendent Reality, but with the help of historical studies of religious traditions.” ${ }^{75}$ In an attempt to avoid both Hick's and Heim's presuppositions about ultimate Reality (that there is only one or there are many), Huang defers to a more sociological or functional approach to the issue of pluralism, one which might bring to mind Emile Durkheim or Peter Berger and their interpretations of religion. For Huang, pluralism is really only useful insofar as it can be used for interfaith dialogue, and seeks to emphasize that "different religious traditions are all different but not to be isolated and all interconnected but not to be universalized.,76 On his model, interfaith

\footnotetext{
${ }^{74}$ One might note that the refusal to accept the privileged language - or indeed any language - of another is actually acceptable within radical pluralism, which includes the possibility that agreement or even conversation is impossible. Within ontological pluralism, such a situation is also accepted, though its goal is to surpass that obstacle for the development of open dialogue.

${ }^{75}$ Yong Huang, "Religious Pluralism and Interfaith Dialogue: Beyond Universalism and Particularism,” International Journal for Philosophy of Religion, Vol. 37, No. 3, (June 1995), 135.

${ }^{76}$ Ibid., 137.
} 
dialogue with this middle ground pluralism is based on mutual learning and teaching. Such a concept is manageable enough, and on the surface I disagree with nothing. But as Huang goes further, he criticizes Heim’s model, saying that “for Heim, since different religions are incommensurable, they have nothing, at least nothing essential, to learn from and teach to each other.” He continues to say that Heim's model doesn’t allow for mutual influence among religious structures and traditions - and it is here that I believe he is incorrect. Heim's model of incommensurable difference does not exist on some noumenal plane where religions are static and unchanging. Rather, Heim's appreciation of differences rests on the idea that the ultimate goals might be completely different and irreconcilable, but that doesn't mean that the traditions and structures that are the means of attaining these goals are. One would be foolish to suggest that expansion, globalization, exposure, and history had had no effect on the development of traditions. Huang's argument that both Hick and Heim are too bogged down in the metaphysical is pointless. It takes a good idea (that a model for pluralism must emphasize both interconnectedness and difference without going to universalism and isolation) and turns it around by wrongly attributing a sort of strong particularism to Heim's model and criticizing it.

I will give Huang credit for his final observation on his pluralism model, though I would attribute it to Heim's rather than his own! He lauds the importance of not endorsing a particular outcome as final ${ }^{77}$; this is what it most important in models of dialogue based on ontological pluralism. The dialogue itself is the end goal - having a conversation where people listen to each other will move people miles in the right direction toward more palatable coexistence.

Regardless of whether you convince anyone that yours is the best way or are in turn convinced of someone else's traditions, the point is that conversation happened, and it happened respectfully while recognizing the validity and the reality of the other's tradition. From here, using the

\footnotetext{
${ }^{77}$ Huang, “Religious Pluralism,” 139.
} 
acceptance model, we can continue to be influenced by and influence others in an interconnected and constantly changing world without losing our own religious traditions. It is in the acceptance model that we can truly maintain religious identity.

\section{On Maintaining Religious Identity}

After exploring the two different approaches to modeling pluralism and thus interfaith dialogue embodied in John Hick and S. Mark Heim, I must explore where the question of identity maintenance fits. Pluralism must first be understood as a real situation, inherent in existence. Without asserting ontological pluralism as the basis for interfaith interaction, there is really no hope of keeping up religious identity, because there is an underlying assumption that some or even all differences can be graded or cast aside as useless. At the outset of accepting pluralism like that, identity is already threatened. Such a pluralism is to be found in Hick's universal approach to pluralism, which posits the true universal as singular, but in practical application, it is the acceptance of merely another interpretation.

Much better for identity is a pluralism like Panikkar’s, Heim’s, and Min’s, which accepts and affirms difference and diversity. Although the dialogue that follows such affirmation is likely to be filled with conflict as people are confronted with incommensurable difference, that conflict is to be expected and accepted as part of the conversation process. As dialogue continues, and the fact that competition for eschatological supremacy is absent, the heat and intensity that accompanies dialogue bent on persuasion or justification will slowly fade. It may never be absent; people like to argue too much for that. But as long as remembering that endgoals vary and preclude no one, arguing can perhaps be reduced. 
Using the acceptance model presents an opportunity to affirm and reaffirm religious identity. In learning about the other, it is possible - and likely - to learn more about the self. The conversations which encourage one to examine one's own traditions can help intensify faith or develop greater intimacy with the transcendent or with one's community. They can also expose one to new ideas by which one can be influenced - perhaps adding a new tile to the cultural mosaic and augmenting one's identity. In doing so, one can continue to participate in the globalization process which increases identity complexity. Increasing complexity does not mean that an old identity is lost, but that one's true identity is developed. Identity is not static, but dynamic.

Practically, following the acceptance model is difficult: how do you move toward affirming difference without feeling that you need to justify your own beliefs? Or how can you disagree with someone and still remain in open and willing conversation? These issues will be the subject of my final chapter, as I examine what some interfaith groups have been and continue to do to invite people to and grow their dialogues.

It is perhaps appropriate to end with a final quotation from Paul Knitter about the importance of diversity, and the fact that interfaith dialogue, while bringing similarities to the foreground, does not seek to do away with differences. In fact, using a model which encourages and affirms difference refutes the need for accommodative practices which launch the strong reactions of fundamentalists.

“The many" cannot be boiled down to "the one.” Yes, different things can be interrelated, connected, and brought into unifying relationships, but never to the point where you lose 
diversity. [...]Diversity dominates unity, and we can be happy it does. For otherwise, life and its evolution not only would get dull but would wither away.,"78

\footnotetext{
${ }^{78}$ Knitter, Introducing Theologies, 175.
} 
Chapter 3:

An Examination of Selected Interfaith Groups

Having explained the concept and salience of religious identity and thus the reason for fears of its erosion, I turned to the issue of interfaith dialogue as a possible cause of that erosion. Interfaith dialogue is based upon the assumption of pluralism, and so after examining philosophical and theoretical models that have come of those who recognize pluralism's influence, it is now time to approach the question of how those models actually manifest on the ground. Do people actually follow along with the models they purport to use? Are they anything like the frameworks developed by theologians and philosophers? Are they even actually interfaith?

As mentioned in the previous chapter, the acceptance model - or dialogue based on an assumption of ontological pluralism - is quite difficult to carry out in actuality. It is one thing to speak philosophically about states of being and ultimate Realities, but having a true and open discussion with actual people is more than a small challenge. Because of that, the variations among interfaith groups are plentiful. In the most general terms, interfaith dialogue consists of interaction between people of different faith backgrounds, ultimately toward a goal of mutually beneficial relationship and understanding. Diana's Eck's definition of an ideally pluralistic society included interfaith dialogue as a necessary part. Here is the fourth point in her description:

Fourth, pluralism is based on dialogue. The language of pluralism is that of dialogue and encounter, give and take, criticism and self-criticism. Dialogue means both speaking and listening, and that process reveals both common understandings and real differences. Dialogue does not mean everyone 
at the "table" will agree with one another. Pluralism involves the commitment to being at the table -with one’s commitments. ${ }^{79}$

This description of the conflict-ridden nature of dialogue is particularly important. The old adage "we must agree to disagree" is apt; coming together to talk about conviction and the unique aspects of identity and faith that differentiate one religion from the next is bound to involve argument. Argument is not necessarily an evil; rather, it means that the heart of whatever one is proposing is rooted in something deep and meaningful. These are exactly the sorts of things that need to be shared to gain insight and understanding of each other. Without this, we will never achieve something like Anselm Min’s “solidarity of others,” which recognizes interdependence and thus promotes peaceful and positive coexistence.

\section{Envisioning Successful Interfaith Dialogue: the Maintenance of Religious Identity}

At the crux of successful interfaith dialogue and the building of relationships through interconnectedness lies the maintenance of religious identity. In order to have a conversation in which each person presents her own arguments successfully, the content of each argument must be important and meaningful enough to be worth defending. This is the "commitment to being at the table with one's commitments” Diana Eck advocates in her definition. True interfaith discourse happens with those convictionists I described in Chapter $1,{ }^{80}$ who are comfortable with and devoted to their religious convictions. Sharing and teaching about those convictions proves that they are important enough to a person to assert even among directly oppositional claims.

\footnotetext{
${ }^{79}$ Diana L. Eck, “What is Pluralism?” The Pluralism Project: Harvard University, pluralism.org

${ }^{80}$ See Chapter 1, page 24ff.
} 
Unsuccessful interfaith dialogue reduces identity complexity in two main ways. (1) Accommodative behavior - or a common-ground approach - leads to homogenization and the deactivation of certain tiles in the identity mosaic rather than the increased activation or addition of new tiles. The accommodative behavior that leads to the narrowing and simplifying of identity is more often the result of one who is not so strongly attached to their beliefs. Such is the way toward the homogenization of identity, wherein many of the differences that create uniqueness are sacrificed for the "greater good" of getting along. (2) The dialogue does not affirm and accept difference, leading to strengthened boundaries around already existing and activated identity indicators, thus increasing intolerance for any not within the selective in-group. (Such a reaction has already been elaborated in discussion of the fundamentalist identity in Chapter 1.)

Both circumstances present a challenge to interfaith dialogue, but it is the first circumstance which is more dangerous, as it masquerades as a success, but is, in fact, a failure. Accommodative behavior, while reducing identity complexity, could have an effect opposite the usual increase in out-group intolerance seen with such a reduction. ${ }^{81}$ Because accommodation practices occur for the purpose of coming together in agreement, they actually widen the ingroup, allowing those of marked difference to be part of a larger single identity. The problem with this is that in doing so, they are no longer being "interfaith," because they no longer acknowledge the heterogeneity which merited the dialogue in the first place. In other words, although accommodation might make for an easier conversation, it doesn't allow the participants in that conversation to be their full selves. Thus, a more complex identity is still preferable, even if what comes with it is conflict and disagreement.

\footnotetext{
${ }^{81}$ Marilynn B. Brewer and Kathleen P. Pierce, “Social Identity Complexity and Outgroup Tolerance.” Personality and Social Psychology Bulletin 31 (2005).
} 
Interfaith dialogue is not necessarily an identity threat. It does, however, become one when the method of approach does not affirm and acknowledge differences. When a group participates in a model like John Hick's, the focus on some form of common ground (for Hick, the ultimate Real) shunts differences aside, left as mere perspectives or interpretations - mere emanations of what is truly important. In doing this, key points of one's beliefs and traditions are denied as relevant to everyday life and they are often either privatized (to the point where strong reactions are necessary to bring them back into the public) or neglected overall, until something that was once important is forgotten in favor of unstrained relations between people who begin to look more and more like one another. It is this sort of homogenization that was of concern to Paul Knitter in the final quote of Chapter 2: "Diversity dominates unity, and we can be happy it does. For otherwise, life and its evolution not only would get dull but would wither away.",82

This chapter aims to explore several groups who claim to be invested in interfaith practices. By exploring their public literature and mission statements, I will examine the success of the implementation of the dialogue models they purport to use. Determining whether they can even be considered interfaith (as per the accommodation model), I can then point to which structures and approaches are best for the continuation of interfaith dialogue in the future.

\section{The International Level: The Hizmet (Gülen) Movement}

The international movement pioneered by Fetullah Gülen is one grounded in the religious tradition of Islam. As with Anselm Min’s global theology of dignity and solidarity, Mr. Gülen’s

\footnotetext{
${ }^{82}$ Paul Knitter, Introducing Theologies of Religions, (New York: Maryknoll, 2002), 175
} 
ideals and values have roots within the religion in which he himself participates; they then branch off and extend into the world at large. Very briefly, Mr. Gülen, born in Erzurum, Turkey, was educated in both modern and religious institutions. He became well-known for his preaching as well as his scholarly pursuits. In time, he began advocating for education as the best means of bringing people together, and rallied people within the communities to support his ideals for educational improvement. ${ }^{83}$ Mr. Gülen's mobilization of resources became the international movement known by outsiders as the Gülen movement and Hizmet (service) movement to its members.

The movement itself is organized around philanthropic outreach, education, and the important ideas of building bridges between Islam and the West. Many different institutions have been developed through the support of participants in the movement, including schools and universities, news and print media, television stations, and humanitarian aid groups. The most important branch for interfaith work is the Journalists and Writers Foundation (JWF), a group created especially for the purpose of creating interfaith dialogue through its six platforms.

As education has been so important in Gülen's own life, so it has been the cornerstone on which Hizmet at large has been built. In his work, Love and Tolerance, Gülen explains:

"The main duty and purpose of human life is to seek understanding. The effort of doing so, known as education, is a perfecting process through which we earn, in the spiritual, intellectual, and physical dimension of our beings, the rank appointed for us as the perfect pattern of creation.”84

\footnotetext{
${ }^{83}$ For further biographical information, there are a number of sources available, including Helen Rose Ebaugh, The Gülen Movement: A Sociological Analysis of a Civic Movement Rooted in Moderate Islam," (New York: Springer, 2010), and Understanding Fethullah Gülen, a short publication by the Journalists and Writers Foundation.

${ }^{84}$ Fethullah Gülen, Toward a Global Civilization of Love and Tolerance, (New Jersey: The Light, Inc., 2006), 202.
} 
Some 1000 schools across the world ${ }^{85}$ have been inspired by his educational philosophy, one which hopes "to educate a generation trained with modern knowledge as well as Islamic morals.” ${ }^{86}$ Both in institutions like the JWF and in the schools Gülen has inspired, religion is not to be ignored.

The main principle on which Hizmet is founded is, undoubtedly, love. The subject of a wide range of Gülen’s written works, love as a connector runs a close parallel to Min’s solidarity of others and to Hick's ultimate Real. It is something which can unite, and bring people together on common ground. It is through this overarching love that Gülen's definition of tolerance arises - one which is more like respect, mercy, generosity, or forbearance ${ }^{87}$ - and which serves as the grounds for warm interreligious dialogue to take place. A good summation of the ideals of Hizmet can be found in the following quote from Love and Tolerance.

"Being tolerant does not mean foregoing the traditions that come from our religion, or our nation, or our history; tolerance is something that has always existed. The Ottomans were faithful both to their religion and to other values and, at the same time, they were a great nation that could get along with other world states. If the people of today, who are civilized, enlightened, and open to the world, are going to fall short of those who loved in that period, then this means they have not understood this age. In this respect, as individuals, as families and as a society, we have to speed up this process that has already begun. I personally believe that even the people who do not share our feeling and thoughts will soften when we go to see them. Thus, in the name of dialogue we can unite on common

\footnotetext{
${ }^{85}$ Helen Rose Ebaugh, The Gülen Movement: A Sociological Analysis of a Civic Movement Rooted in Moderate Islam," (New York: Springer, 2010), 97. Estimates on the number of schools is very difficult, and though lists are complete for some countries, they are not for others. An interesting compilation of such lists can be found at http://turkishinvitations.weebly.com/every-continent-but-antarctica-the-numbers.html.

${ }^{86}$ Ebaugh, 34.

${ }^{87}$ Gülen, Love and Tolerance, 34.
} 
ground and shake hands with all. This is because the things that God gives most value to are human beings, love, and compassion.” 88

All such ideals are very pretty words, but carried out by the people, separated from their inspirational leader, the ideals seem muted in favor of bringing as much institutional good to people as possible. This latter is in not a bad thing - I hope to improve the educational and economic standards for the world as well! - but in focusing on institution-building, the engaging and reflective interfaith component is often left unrealized except in events and conferences organized by the Journalists and Writers Foundation. The general membership of the Hizmet movement is not nearly as involved.

The Los Angeles based branch of the Hizmet movement, the Pacifica Institute, holds many events and activities centered on Mr. Gülen’s common ground approach. One such event in which I took part was an intercultural trip to Turkey, the goal of which was to bring together people of different faiths in dialogue and discussion while seeing the work the movement had been doing in its home country. However, in visiting Turkey and being privy to many institutional visits, I found that there was quite a difference between the publicized institutional goals based on Mr. Gulen's call for dialogue and the situation on the ground. Most participants in the local circles are focused more on social action, recruiting, or gaining financial contribution than they are on the higher goals of bridge formation. Hande, a physician and longtime member of the movement residing in Nigde, said that "the emphasis is on doing, as well as lived Islam." For Hande, the story is more about sharing and spreading the responsibility for humanity. She compared the Hizmet movement to a relay competition, passing benevolent action from person to person. She related an anecdote about helping someone in her clinic as a youth, and then finding

\footnotetext{
${ }^{88}$ Gülen, Love and Tolerance, 43.
} 
out that person became a doctor helping others at his own clinic. ${ }^{89}$ A story like Hande’s demonstrates the good works being carried out, but also the failure to engage in anything beyond those good works.

Religion - and religious difference - was only brought up in dialogue as a sort of general acknowledgement that we came from very different backgrounds. But once that difference was acknowledged, it was shunted to the side, nearly explicitly. Instead, the love and humanity common ground was emphasized, and the very possibility of an engaging discussion of religious variety was dismissed. Necip, a local circle leader and representative of the board at one of the Hizmet tutoring centers in Izmir, stated outright that "religious identity should be secondary,” that it was "brotherhood and humanity that should be number one."90

The efforts of this movement, while absolutely laudable, are not truly interfaith. Interfaith dialogue and interaction are stated as goals of Gülen’s original idealism, but they are carried out in a way that doesn't actually allow for true reflection and engagement. The Hizmet movement acknowledges diversity and pluralism, but in a Hickian rather than Heimian manner: love and humanity are elevated as the ultimate Real that everyone should see in order for true communion to take place. Religious identity is subsumed under the desire for philanthropy and institution building. Given Diana Eck’s fourth point, and the discussion in Chapter 2 about acceptance and affirmation, I would classify the Hizmet movement as rooted in interfaith idealism, but not actually interfaith in its activity.

\section{The National Level: Interfaith Youth Core}

\footnotetext{
${ }^{89}$ Interview with Hande, May 2013, Nigde, Turkey. I have changed the name to preserve anonymity, per mutual agreement.

${ }^{90}$ Interview with Necip, May 2013, Izmir, Turkey. I have changed the name to preserve anonymity, per mutual agreement.
} 
The second interfaith group I will discuss is the Interfaith Youth Core (IFYC), a national organization founded by author and advocate Eboo Patel, incorporated in 2002. While IFYC affiliates with groups outside the United States, it is the domestic organizations which are of particular interest here, since they make up the bulk of the group's endeavors. Such projects include speeches, service learning, and interfaith leadership training. With an explicit goal to develop interfaith relationships, IFYC has partnered with many institutions, including the White House, with President Obama’s interfaith initiative, “The President's Interfaith and Community Service Campus Challenge.” This challenge, in association with Better Together, IFYC’s student-led campaign for interfaith action, works with higher education institutions across the country to commit to a full year of interfaith and community service programing. As of the inaugural report for the 2011-12 and 2012-13 years, over 242 institutions participated. ${ }^{91}$

Activity within this IFYC/Better Together/President's Challenge is based on “interfaith action that is action-focused, seeking to create opportunities for people of different religious and non-religious identities to work together on issues of common concern."92 At the heart of this partnership is the insistence that the best interfaith interaction will come from colleges and universities and the students that attend them. In a recent article, Eboo Patel and Cassie Meyer explain their reasoning.

Colleges and universities often serve as microcosms of America’s broader religious diversity, where students of different faiths regularly interact with one another in close quarters, often for the first time. This happens in a space where they are encouraged to question, challenge, and explore their own identities and those of others. Further, if they practice a faith in college, it is often because it is specifically their choice, rather than as a result of family expectations of habit.

\footnotetext{
${ }^{91}$ U.S. Department of Education, Center for Faith-Based and Neighborhood Partnerships, The President's Interfaith and Community Service Campus Challenge Inaugural Report, Washington, D.C., 2013.,x.

${ }^{92}$ Inaugural Report, xi.
} 
In other words, questions of identity, diversity, and relationship are raised simply by the campus context. $^{93}$

For this group, interfaith interaction is aimed toward people who will (ideally) intentionally interact with each other with faith questions on their tongues, not something kept hidden in the background, but something to be shared and reflected upon as they work toward a common goal.

IFYC’s vision of pluralism is based at least in part on Diana Eck’s definition; it draws from her vision of pluralism as an achievement of people engaging their diversity toward a common end. ${ }^{94}$ This can be achieved by interfaith cooperation and interfaith leadership, especially through building relationships. These relationships are founded on the principles of

1) Respect for people’s diverse religious and non-religious identities, 2) Mutually inspiriting relationships between people of different backgrounds, and 3) Common action for the common good. ${ }^{95}$ It is point 3) which draws my eye as potentially problematic. While all other principles and dedication to maintaining religious identity while building relationships point to an acceptance model type function, the devotion to service learning and humanitarian efforts can, I believe, undermine all that.

I spoke with May, who is an employee of IFYC, about this issue in particular. After attending events and updates on the status of the President's Challenge in this academic year, I noticed that many participants and potential participants were voicing the same concern: what is interfaith about the work we are doing? People would get together, and yes, they would be from disparate religious backgrounds, but in focusing on completing their goals (distributing food to the homeless, building houses, tutoring, or environmental clean-up), the exchange of information

\footnotetext{
93 Eboo Patel and Cassie Meyer, “The Civic Relevance of Interfaith Cooperation for Colleges and Universities,” Journal of College and Character, Vol. 12, No. 1, February 2011, 6.

94 “Civic Relevance," 2,

95 “The Framework,” IFYC: About the Movement, last updated January 24, 2014. http://www.ifyc.org/about
} 
and engagement in dialogue often fell by the wayside. Technically, interfaith action had happened, but it could have been any group coming together to serve. When I asked May about this, she responded:

“...that perennial problem still exists, which is people are familiar with service learning $[\ldots]$ and it is an issue of a learning curve and willingness to push the envelope on having that conversation. We do a lot of training in the ILI [Interfaith Leadership Institutes] around "how do you build interfaith into the service work that you're doing? How do you make it explicit?” [...] So what we're trying to do is create resources and advise people on ways to think about building in that interfaith reflection component to the service learning work that they’re doing." ${ }^{96}$

This problem, then, is one that IFYC has been dealing with from its inception. Making interfaith dialogue and interaction explicit is something consistently on their minds, and much of their time and energy is spent on developing resources just to the purpose of solving this problem. One particular resource, "Facilitator's Tools: Interfaith Conversations on Shared Values" ${ }^{97}$ lays out a series of talking points to get dialogue moving in a safe and welcoming environment. A basic suggestion is storytelling as a means of dialogue, sharing experiences on the shared service project and then discussing motivation - were you inspired from your faith tradition or moral perspective? These sorts of discussions open the possibility of addressing differences in a place where the sharing of them will not be stopped in favor of avoiding conflict. Rather, the variety of responses and differences make the conversation richer.

On the ground, however, even such helpful resources can fail. Focusing an entire organization around the ultimate end-goal of service can be, in the same way that Hick's universalism is, deleterious to the maintenance of religious identity. Thus a very careful balance

\footnotetext{
${ }^{96}$ Interview with May, March 25, 2014. I have changed her name to preserve anonymity, per mutual agreement.

97 "Facilitator's Tools: Interfaith Conversations on Shared Values," IFYC Tools for Campus Impact, 2013. http://www.ifyc.org//sites/default/files/u4/SharedValues_small.pdf
} 
must be struck between using the common ground of service as a jumping-off point and allowing it to overwhelm any movement toward true dialogue.

Overall, I believe the IFYC, along with Better Together and the President’s Challenge, are good examples of interfaith movements. Although they face many challenges in applying the theoretical acceptance model approach in a practical setting, they are making strong efforts in the cause. Rather than making service equivalent to an ultimate Real, IFYC includes it as a shared value, bringing people together into unification rather than unity.

\section{The Local Level: Muslims and Methodists (M\&Ms)}

The final interfaith group I will explore is a very localized one. Its home base is in Rancho Cucamonga, California, and it has been in existence in its current form for approximately three years. Originally started in the wake of 9/11, one of the current (Muslim) members' fathers had a very good relationship with someone from the Methodist church and they entered into a plan for an interfaith group between their two communities. This group met off and on for several months before the project was given up due to lack of interest and key members having to relocate. Later, Omar, the son of one of the founding members decided to rekindle the project, bringing many people from both communities together mostly for meals and fellowship. Though the group constituency has shifted somewhat over time, the core founding members have stayed the same throughout the shifts caused by lost interest, residential mobility, and new members. The number of participants at each meeting has gone as high as thirty, but on average, twelve to twenty people attend each monthly meeting. ${ }^{98}$

\footnotetext{
${ }^{98}$ Interview with M\&Ms members: Omar and Bob, March 08, 2014. Omar and Bob were kind enough to elaborate not only on the group's origins, but also on its current structure and organization.
} 
The group meets once a month, rotating among the homes of the members. It is largely informal, still centered around meals and fellowship, though there is some small amount of structure, in the form of a presentation given by volunteers. Sometimes this presentation is a narration of an event or a faith journey. It might also be discussion of a current event that has some bearing on religious freedoms or practices. After such presentations, a general question and answer dialogue is created, serving to elaborate or clarify points of confusion. Because the group is small and on nearly familial terms, there is rarely any sort of conflict or disagreement which warrants heated words. But the atmosphere they have created is one in which, should any such dispute arise, it would likely be handled with gentle warmth and open discussion.

Because the M\&Ms are a small unincorporated group, I could not search publications or items within the public domain to find any sort of list of guiding principles by which they officially maintain their organization. Neither do they use any particular framework or model to structure themselves. But after studying some of the pluralism and dialogue models out there, I would say that theirs is most like Heim's acceptance model. They accept differences - are keen to understand them better and develop strong relationships knowing that they will never see from the exact same perspective. Martha, in fact, asserted that rather than feeling uncomfortable at the differences, “[seeing the differences] has forced me to go deeper into my own Christian practice." She explained that "we still try to say what's unique about us and what we are sharing in the relationship, but it's more than trying to find our least common denominator."99

To a small extent, because their group is based on trust and friendship over identity specifically, ${ }^{100}$ one could argue that they take something like a common ground approach. Sharing stories or religious experiences and learning that there is something familiar from one to

\footnotetext{
${ }^{99}$ Interview with M\&Ms members: Martha, March 08, 2014.

${ }^{100}$ Interview with M\&Ms members, March 08, 2014, Bob speaking.
} 
another could also be common ground. However, the free discussion, and insistence on maintaining unique perspectives makes, like in the IFYC, the common ground a mere jumpingoff point, rather than an ultimate goal. At one point, Fatmah, a Muslim, was sharing a story about the process of her marriage, and how that affected her faith. After taking time to explain and discuss what the marriage process was in contrast to the Christian one, Bob, a Methodist, made a comment about how some of her actions were mirrored and encouraged in the New Testament. He jokingly said that she would make a good Christian, and the group immediately ruptured into laughter and mocking admonitions of "hey - no proselytizing!" and "that's against the rules!” The maintenance of each faith tradition even in light of better understanding - even of similarities - of the other is at the heart of the discussions of the group. What they do is truly engaging and listening - interfaith dialogue in the most successful way.

\section{Evaluation}

Although all three groups purport to have true interfaith dialogue as a defining principle, it seems that only the latter two can uphold it, and the smallest local group manages this most successfully. IFYC still struggles, and I believe it is largely because it focuses on service rather than conversation and knowledge exchange as the central tenet. Perhaps this is because of the issues that arise when dialogue reaches an impasse. Part of the problem for any interfaith work is the difficulty of absolute truth claims; while Heim's acceptance model allows for multiple truth claims to be valid, such an understanding is indeed very difficult to carry out in practice. May, in talking about this problem within IFYC, said:

I think that interfaith work has to be able to absorb the reality of absolute truth claims. That's one of those deep differences [...] I think the challenge in the interfaith movement is it’s largely 
oppositional to absolute truth claims. It, generally speaking, approaches more religiously conservative groups with the attitude of if you're not going to be inclusivist enough for us, then you don't have a place in the movement. ${ }^{101}$

Within this paradigm of respecting various religious identities is the challenge of accepting that other truth claims are acceptable and do not infringe upon our own. By building stronger relationships based on trust and shared stories, the M\&Ms group is opening the path for acceptance of conflicting truth claims. May stated that she couldn't quite go so far as to say that, as Heim proposes, all truth claims are true. Rather, she said that instead, we must approach the rival truth claims with respect and curiosity and a desire to learn more. “...And maybe it changes the way that I think about ultimate questions in my own life, but that doesn't mean that I have to come over to your side. I think that creates a world in which we can maintain our unique identities and our unique beliefs.”102 In the same way then that globalization may increase identity complexity, influencing and altering the identity we have come to hold so dear, interfaith dialogue can do the same in encouraging others to think in a way different from their traditional patterns.

Influencing or increasing the complexity of identity does not erode it. Instead, it encourages one to think more in depth about what one's identity really means and what it is that would be problematic to lose. That option isn’t even available in common ground approaches like the Hizmet movement, wherein the separation of religion from all the institutions and the understanding of religion as merely a side effect or a secondary aspect of being leave religious identity as something that is either never to change or perhaps never to be thought of. Perhaps it is even weakened by this lack of consideration. And while a weak identity is capable of bridging

\footnotetext{
${ }^{101}$ Interview with May, March 25, 2014. I have changed her name to preserve anonymity, per mutual agreement.

102 Interview with May, March 25, 2014.
} 
gaps by closing the gap somewhat through homogenization, it cannot retain the important diversity that necessitates confrontation and dialogue in the first place.

One of the ladies from M\&Ms made the following statement, one I think is particularly appropriate for closing:

"Generally, people think that those of weak religious identities build bridges. Then the people of strong identity put up walls. What we need is people of strong religious identity building bridges, and that is what we're doing."

It is indeed those of strong identity and those who seek to maintain that identity who are able to engage in the most successful interfaith dialogue. Maintaining the diversity which inspired the need for dialogue and new understanding in the first place, such bridge builders are the ones who use difference and affirmation as the best supports to keep the bridge in use for future participants.

${ }^{103}$ Interview with M\&Ms members: Martha, March 08, 2014. 
Conclusion: Final Thoughts.

Although it is quite a challenge, religious identity can indeed be maintained within the bounds of interfaith dialogue. The threat it poses to identity can be nullified by a change in methodology from one which utilizes accommodation practices, reducing identity complexity and encouraging homogeneity, to one which affirms and celebrates difference. The acceptance model allows for interfaith dialogue premised on the open acknowledgement that not all differences are reconcilable - and that is not necessarily a problem. Instead, by coming to an understanding that variant beliefs have ultimately distinct end-goals, dialogue can be encouraged without having to resort to conversion attempts, competition for access to the divine, or the sacrifice of aspects of identity for the sake of finding some common ground. Of course, conflict is inevitable because different religious traditions and belief systems will not necessarily be compatible or even logically consistent. And while reconciling oneself to irreconcilable differences is something of a challenge, it is part of developing deeper and strong relationships based on the open acknowledgement that diversity makes us who we are.

Besides the difficulties encountered because of accommodation rather than acceptance, interfaith dialogue suffers from the uncertainty of how to approach people of little conviction, who do not consider themselves religious, but must still interact with those who do. It is here that we must remember that the definition of religion is as ambiguous as identity - that included in religion are belief systems which do not conform to traditionally understood systematic theologies. The beliefs and values of those who consider themselves non-religious conflict just as much with those beliefs and values of those of particularly strong religious identity. Interfaith dialogue is not solely for convictionists, though much of the effort toward true dialogue based on 
affirmation and acceptance comes from convictionists, who wish to maintain their identity but still engage in conversation with the pluralistic world.

Actualizing interfaith dialogue based on the acceptance model and rooted in ontological pluralism not an easy process. It often seems enough to focus on one shared goal - humanitarian aid, or universal love - to get along with others. But simply getting along is not enough, especially when doing so leads to a dialogue that isn't truly interfaith at all. If faith isn't even mentioned, reflected upon, or confronted when working together to achieve a common goal, what then is interfaith about it? The Hizmet movement illustrates this fairly well, in that building institutions for the betterment of society is an impressive task to take on, but it could be accomplished by any group of people rooted in a national identity, a family identity, or a careerbased identity. Without the explicit drive toward discussion about and inquiry into faiths other than one's own, there is not much point in labeling an organization interfaith.

Interfaith dialogue seems to work best on a localized level, where building relationships based on trust and a questions-welcome atmosphere leads to a mutual understanding and appreciation of the different faiths represented. When an organization becomes so large that it's programs must be standardized and reproduced, much of the opportunity for personal exchange and sharing disappears, replaced by mass-produced ideas that are designed more for the sake of doing good in the world than in engaging in true interfaith dialogue. Such seems to be the case with the Interfaith Youth Core, who tries to explicitly encourage dialogue, but is thwarted on the ground level by people unwilling or unable to carry out the organizational goals. Perhaps IFYC would do well to take note of the small-group approach of the M\&Ms, at least for preliminary meetings before large projects take place, distracting participants from anything but the completion of whatever service directive they have been given. I do believe IFYC is doing a 
much better job than many interfaith groups, especially with their development of resources to make the principles on which they operate explicit.

Interfaith dialogue as practiced through the acceptance model is vitally important for the world at large because it does make maintaining religious identity possible. And in a world that is all the more interesting for its diversity, we ought to do what we can to maintain that diversity and not bring our evolution to a stalemate by allowing it to disappear merely for the sake of coexistence. 
Bibliography

Almond, Gabriel A., Scott R. Appleby, and Emmanuel Sivan. Strong Religion: The Rise of Fundamentalisms around the World. Chicago: University of Chicago Press, 2003.

Asad, Talal. "French Secularism and the "Islamic Veil Affair,”” in The Hedgehog Review, Spring \& Summer. 2006, 93-106.

Aslan, Reza. How to Win a Cosmic War: God, Globalization, and the End of the War on Terror. New York: Random House, 2009

Berry, John W., Ype H. Poortinga, Seger M. Breugelmans, Athanasios Chasiotis, and David L. Sam. Cross-Cultural Psychology: Research and Applications, $2^{\text {nd }}$ edition. Cambridge: Cambridge University Press, 2011.

Berry, John W. (2000). Cross-cultural psychology: A symbiosis of cultural and comparative approaches. Asian Journal of Social Psychology, 3 (2000): 197-205.

Brewer, Marilynn B. and Kathleen P. Pierce. “Social Identity Complexity and Outgroup Tolerance.” Personality and Social Psychology Bulletin 31 (2005): 428-437.

Casanova, Jose. “The Secular, Secularizations, and Secularisms.” In Rethinking Secularism. Edited by Craig Calhoun, Mark Juergensmeyer, and Jonathan Van Antwerpen. Oxford: Oxford University Press, 2011.

Chao, Georgia and Henry Moon, “The Cultural Mosaic: A Metatheory for Understanding the Complexity of Culture” in Journal of Applied Psychology, 90 (2005): 1128-1140.

Geertz, Clifford. The Interpretation of Cultures: Selected Essays by Clifford Geertz. New York: Basic Books, Inc. Publishers, 1973. 
Deaux, Kay. “Reconstructing Social Identity,” Personality and Social Psychology Bulletin 19 (1993): 4-12.

Duara, Prasenjit. “The Historical Roots and Character of Secularism in China” in The Newsletter, Issue 54, Summer 2010, International Institute for Asian Studies. http://www.iias.nl/the$\underline{\text { newsletter/article/historical-roots-and-character-secularism-china }}$

Ebaugh, Helen Rose. The Gulen Movement: A Sociological Analysis of a Civic Movement Rooted in Moderate Islam. New York: Springer, 2010.

Eck, Diana L. “What is Pluralism?” The Pluralism Project: Harvard University, pluralism.org Gülen, Fethullah. Toward a Global Civilization of Love and Tolerance. New Jersey: The Light, Inc., 2006.

Heim, S. Mark. Salvations: Truth and Difference in Religion. New York, Maryknoll, 1995.

Heine, Steven J., Darrin R. Lehman, Hazel Rose Markus, and Shinobu Kitayama, “Is There a Universal Need for Positive Self-Regard?” in Psychological Review, 106:4 (1999):766794.

Held, David \& Anthony McGrew, David Goldbatt \& Jonathan Perraton, Global Transformations: Politics, Economics and Culture. Stanford: Stanford University Press, 1999.

Hick, John. An Interpretation of Religion: Human Responses to the Transcendent, Second Edition. New Haven: Yale University Press, 2004.

Hick, John. Problems of Religious Pluralism, New York: St. Martin’s Press, 1985.

Hofstede, Geert. Cultures and Organizations: Software of the Mind: Intercultural Cooperation and its importance for survival, 3rd Edition. New York: McGraw Hill 2010. 
Hong, Ying-yi, Michael W. Morris, Chi-yue Chiu, and Veronica Benet-Martinez.. "Multicultural Minds: A Dynamic Constructivist Approach to Culture and Cognition.” American Psychologist, 55:7 (2000): 709-720.

Huang, Yong. "Religious Pluralism and Interfaith Dialogue: Beyond Universalism and Particularism.” International Journal for Philosophy of Religion, 37:3 (June 1995), 127144.

Huntington, Samuel P. The Clash of Civilizations and the Remaking of World Order. New York: Touchstone, 1997.

Kashima, Yoshihisa, and Michele Gelfand. “Culture: A Brief History of Meaning in Psychology.” Culture in Psychology. 2011

King, Pamela Ebstyne. "Religion and Identity: The Role of Ideological, Social, and Spiritual Contexts.” Applied Developmental Science, 7:3 (2003): 197-204.

Paul Knitter, Introducing Theologies of Religions. New York: Maryknoll, 2002.

Kunst, Jonas R. and David L. Sam. “Expanding the Margins of Identity: A Critique of Marginalization in a Globalized World” International Perspectives in Psychology, 2 (2013): 225-241.

Liebman, Charles. “Extremism as a Religious Norm.” Journal for the Scientific Study of Religion, 22:1 (1983): 75-86.

Marty, Martin E. “The Role of Religion in Cultural Foundations of Ethnonationalism.” In Religion, Ethnicity, and Self-Identity: Nations in Turmoil, Edited by Martin E. Marty and R. Scott Appleby. Hanover, NH: University Press of New England, 1997. Markus, Hazel Rose and Shinobu Kitayama, “Culture and the Self: Implications for Cognition, Emotion, and Motivation,” in Psychological Review, Vol. 98, No. 2. 1991: 224-253. 
Min, Anselm. “Loving without Understanding: Raimon Panikkar’s ontological pluralism.” International Journal for Philosophy of Religion 68 (2010): 59-75.

Min, Anselm. The Solidarity of Others in a Divided World. New York: T\&T Clark International, 2004.

Panikkar, Raimon. The Intrareligious Dialogue. New York: Paulist Press, 1978.

Panikkar, Raimon. The Experience of God: Icons of the Mystery. Minneapolis: Augsburg Fortress, 2006.

Patel, Eboo and Cassie Meyer. "The Civic Relevance of Interfaith Cooperation for Colleges and Universities.” Journal of College and Character, 12:1 (2011): 1-9.

Phillips, D.Z. "Religious Beliefs and Language Games.” Wittgenstein and Religion. London: The Macmillan Press LTD, 1993.

Phillips, D.Z. "Philosophy’s Radical Pluralism in the House of Intellect - A Reply to Henk Vroom” D.Z. Phillips' Contemplative Philosophy of Religion: Questions and Responses, Edited by Andy F. Sanders. Abingdon: Ashgate Publishing Group, 2007.

Ozyurt, Saba. "Negotiating Multiple Identities, Constructing Western-Muslim Selves in the Netherlands and the United States,” in Political Psychology 34 (2013).

Sirin, Selcuk R. and Michelle Fine, Muslim American Youth: Understanding Hyphenated Identities through Multiple Methods. New York: New York University Press, 2008.

Shweder, R. A. (1990). “Cultural psychology: What is it?” In Cultural Psychology: Essays on comparative human development, Edited by J.W. Stilger, R. A. Shweder, \& G. Herdt. Cambridge, MA: Cambridge University Press, 1990.

Tamney, Joseph B. and Stephen D. Johnson. “Consequential Religiosity in Modern Society.” In Review of Religious Research, 26:4 (1985): 360-378. 
Taylor, Charles. “Western Secularity.” In Rethinking Secularism, Edited by Craig Calhoun, Mark Juergensmeyer, and Jonathan Van Antwerpen. Oxford: Oxford University Press, 2011.

Tylor, Edward B. Primitive Culture: Researches into the development of mythology, philosophy, religion, language, art, and custom, Sixth Edition. London: Murray, 1920.

Ysseldyk, Renate, Kimberly Matheson, and Hymie Anisman. "Religiosity as Identity: Toward and Understanding of Religion from a Social Identity Perspective.” Personality and Social Psychology Review 14 (2010): 60-71.

U.S. Department of Education, Center for Faith-Based and Neighborhood Partnerships, The President's Interfaith and Community Service Campus Challenge Inaugural Report, Washington, D.C., 2013.

“The Framework,” IFYC: About the Movement, last updated January 24, 2014. http://www.ifyc.org/about

“Facilitator's Tools: Interfaith Conversations on Shared Values," IFYC Tools for Campus Impact, 2013. http://www.ifyc.org//sites/default/files/u4/SharedValues_small.pdf 